\title{
El Niño Impacts on Precipitation in the Western North Pacific-East Asian Sector
}

\author{
CHIA CHOU \\ Research Center for Environmental Changes, Academia Sinica, and Department of Atmospheric Sciences, \\ National Taiwan University, Taipei, Taiwan \\ Li-FAN HUANG \\ Research Center for Environmental Changes, Academia Sinica, Taipei, Taiwan \\ JIEN-YI TU \\ Department of Atmospheric Sciences, Chinese Culture University, Taipei, Taiwan \\ LISHAN TSENG \\ Department of Earth Sciences, National Taiwan Normal University, Taipei, Taiwan \\ Yu-CHIEH HSUEH \\ Department of Atmospheric Sciences, National Taiwan University, Taipei, Taiwan
}

(Manuscript received 30 May 2008, in final form 19 October 2008)

\begin{abstract}
In this study, the western North Pacific-East Asian (WNP-EA) rainfall anomaly induced by the strong El Niño in 1982-83, 1991-92, and 1997-98, and its association with the mean state, are examined. Over the northern part of the WNP-EA region (north of $20^{\circ} \mathrm{N}$ ), which is dominated by southwest-northeast tilting frontal systems, positive rainfall anomalies from the fall before the El Niño peak phase (year 0) to the first wet period after the peak phase (year 1) are affected by low- and midlevel horizontal moisture convergence anomalies induced by low-level anticyclonic circulation anomalies over the WNP region that are associated with El Niño. Over the southern part of the WNP-EA region (south of $20^{\circ} \mathrm{N}$ ), which is dominated by tropical convection, positive precipitation anomalies in the first and second wet periods of year 0 and negative precipitation anomalies from the fall of year 0 to the second wet period of year 1 are associated with the variation of the net energy into the atmosphere, which is mainly contributed to by local evaporation anomalies. The mechanisms for inducing the precipitation anomalies over both northern and southern parts of the WNP-EA region are similar to the mechanisms of the mean precipitation in each rainy period, but the detailed processes for the southern WNP-EA precipitation anomalies are more complicated, particularly in summer. In the first wet periods of years 0 and 1 and the fall of year 0 , the precipitation anomalies are induced by evaporation anomalies that are contributed to by similar effects of sea surface temperature (SST) and wind speed anomalies. In the second wet period of years 0 and 1 , on the other hand, near-surface wind speed anomalies affect precipitation via the process of evaporation. These wind speed anomalies are associated with the concurrence of the low-level circulation anomalies over the WNP region and the Asian summer monsoon trough. The SST anomalies are merely a response to evaporation and downward solar radiation anomalies. The dependence of the rainfall anomalies on the mean state, that is, similar causes for the rainfall mean and anomalies in each rainy period, implies that the mean state plays a key role in simulating the interannual variation over the WNP-EA region.
\end{abstract}

Corresponding author address: Chia Chou, Research Center for Environmental Changes, Academia Sinica, P.O. Box 1-48, Taipei 11529, Taiwan.

E-mail: chiachou@rcec.sinica.edu.tw

\section{Introduction}

The western North Pacific-East Asian (WNP-EA) climate shows a strong interannual variation, with and without the presence of El Niño-Southern Oscillation. With the influence of ENSO, the rainfall associated 
with the Asian summer monsoon exhibits a very strong interannual variation (e.g., Chang et al. 2000a,b; Chou et al. 2003; Lau et al. 2000; Lau et al. 2004; Wang et al. 2000; Wang et al. 2001; Wang and Zhang 2002 and references therein). In the growing year of El Niño, the western North Pacific summer monsoon rainfall tends to increase, due to a low-level cyclonic circulation anomaly over the WNP and the Philippine Sea. In the decaying year of El Niño, on the other hand, the changes in rainfall are reversed (decreased), due to a low-level anticyclonic circulation in summer. The reversal of the low-level circulation anomalies occurs around September of the El Niño growing year, a coupling with the seasonal cycle (e.g., Chen et al. 2007; Chou 2004; Lau and Nath 2006; Wang and Zhang 2002). In other seasons, such as fall, winter, and spring, rainfall is also affected by ENSO (e.g., Wang et al. 2000; Wu et al. 2003; Zhang and Sumi 2002). In addition to the typical ENSO events, a pseudo-El Niño (El Niño Modoki) can also affect the WNP-EA climate (Ashok et al. 2007; Weng et al. 2007). For instance, the WNP summer monsoon is enhanced and the East Asian summer monsoon is reduced during the positive phase of this phenomenon. Without the ENSO influence, the summer rainfall over these areas also shows a strong interannual variation (e.g., Chou et al. 2003; Geng et al. 2000; Park and Schubert 1997), which can be attributed to the Indian dipole pattern (e.g., Guan and Yamagata 2003; Li et al. 2005; Saji and Yamagata 2003; Yoo et al. 2006), a biennial oscillation (e.g., Meehl et al. 2003; Shen and Lau 1995), snow cover of the Tibetan Plateau and Eurasia (e.g., Hsu and Liu 2003; Liu and Yanai 2002; Wu and Kirtman 2007), and a Pacific-Japan (PJ) pattern (e.g., Nitta 1987; Lau 1992; Huang and Sun 1992; Nitta and $\mathrm{Hu}$ 1996).

How can El Niño affect the WNP-EA climate, a region far away from the main warm SST anomalies over the equatorial eastern Pacific? Low-level circulation anomalies over the WNP and the Philippine Sea, which persist through almost the entire El Niño period of two years, play a major role in connecting the climate over these two regions (e.g., Kang 2004; Lau et al. 2004; Sumi et al. 2004; Wang et al. 2000; Wu et al. 2003). In the El Niño peak phase, low-level circulation anomalies are usually associated with a Rossby wave response to suppressed convection induced by a weakening of the Walker circulation and cold SST anomalies over the western Pacific warm pool (Chou 2004; Wang et al. 2000; Wang and Zhang 2002; Watanabe and Jin 2002).

El Niño impacts on precipitation depend on the mean circulation over the WNP-EA region in each season even though the anomalous fields could be the same.
Over the WNP-EA region, roughly defined as the region $10^{\circ}-40^{\circ} \mathrm{N}, 110^{\circ}-150^{\circ} \mathrm{E}$, five natural rainy seasons have been identified: winter, spring, the first wet period (pre-mei-yu/mei-yu season), the second wet period (typhoon season), and fall (Chen and Chen 2003; Chou et al. 2009, hereafter CHTTT; Yeh and Chen 2000). Thus, our focus here is on how El Niño affects the precipitation over this region in each natural season via the interaction between the mean state and the anomalous fields. We will also examine the differences and similarities of the mechanisms inducing mean and anomalous precipitation. We first review the seasonal variation of precipitation and possible processes associated with precipitation over this region because the El Niño impacts on the precipitation may depend on the mean state of each season. Based on this review of the seasonal variation of precipitation, we further examine possible processes for inducing the interannual variation of precipitation associated with strong El Niño events, which usually has a strong teleconnection with the WNPEA climate. The datasets that we used in this study have relatively finer temporal resolutions, such as 6-hourly and pentad intervals, so we can accurately identify El Niño impacts not only on the spatial distribution but also on temporal variations. The datasets used here are briefly described in section 2, followed by a description of the seasonal cycle and interannual variation of the precipitation over the WNP-EA region. Processes associated with rainfall anomalies over the northern and southern parts of the WNP-EA region are discussed in sections 4 and 5, respectively. Discussion and conclusions are presented in section 6 .

\section{Data}

To study the interannual variation of precipitation over the WNP-EA region, the Climate Precipitation Center (CPC) Merged Analysis of Precipitation (CMAP) (Xie and Arkin 1997) pentad precipitation is used as the primary dataset. The CMAP precipitation is from 1979 to 2006 and global coverage is at a resolution of $2.5^{\circ} \times 2.5^{\circ}$. Besides precipitation, other variables such as winds, air temperature, and surface heat fluxes are derived originally from a 28-yr (1979-2006) 6-hourly National Centers for Environmental Prediction-Department of Energy (NCEP-DOE) Reanalysis-2 dataset, hereafter referred to as NCEP2 (Kanamitsu et al. 2002). In other words, both linear terms (such as wind components) and nonlinear terms (such as horizontal moisture convergence) are calculated 6 hourly and then averaged into a pentad temporal resolution. Thus, the transient effect is included in the nonlinear terms. A weekly optimum interpolation (OI) sea surface temperature (SST) with $1^{\circ}$ spatial resolution 
from November 1981 to December 2006 (Reynolds et al. 2002) is interpolated into a pentad resolution consistent with the precipitation data. To study the association of the WNP-EA climate with El Niño, the three strongest El Niño events during 1979-20061982-83, 1991-92, and 1997-98-are analyzed, along with the composite of these three El Niño events. The choice of El Niño is based on the Niño-3.4 index in December-February (DJF). Most results shown here are a composite of the three El Niño events and are consistent with the results for each individual El Niño. Since the peak phase of El Niño is around the end of the year, the year before the peak phase $(1982,1991$, 1997 ) is defined as a growing year (year 0) and the year after the peak phase $(1983,1992,1998)$ as a decaying year (year 1).

\section{Seasonal and interannual variations}

\section{a. Seasonal variation}

Over the WNP-EA region, five distinguishable natural rainy periods are commonly defined: spring, the first and second wet periods, fall, and winter (Chen and Chen 2003; CHTTT; LinHo and Wang 2002). Figure 1 shows the seasonal variation of the pentad precipitation anomalies over $110^{\circ}-150^{\circ} \mathrm{E}$. We note that the domain here is slightly wider than that used in CHTTT because the precipitation anomalies associated with El Niño usually extend to the east of $140^{\circ} \mathrm{E}$ in summer. However, this modification does not change the onset time of each rainy period. In the spring period, from mid-March to mid-May (from the 13 th to 27 th pentads), a major rainband found between $23^{\circ}$ and $33^{\circ} \mathrm{N}$ is associated with a frontal system. In mid-May (the 28th pentad), strong rainfall (greater than $6 \mathrm{~mm}$ day $^{-1}$ ) occurs around $20^{\circ}-$ $30^{\circ} \mathrm{N}$ and moves northward gradually, which is associated with the pre-mei-yu/mei-yu front (Ding and Chan 2005). This is the onset of the first wet period, which ends around late July (the 41st pentad). Meanwhile, strong tropical convection is also found around $5^{\circ}-15^{\circ} \mathrm{N}$, which is consistent with the South China Sea and the WNP summer monsoons. The tropical convection in the south abruptly jumps northward to $20^{\circ} \mathrm{N}$ (the $10 \mathrm{~mm}$ day $^{-1}$ contour) late in July (the 42nd pentad). This is associated with the development of the WNP summer monsoon gyre, which marks the beginning of the second wet period. Almost at the same time, the pre-mei-yu/ mei-yu front in the north disappears. The WNP summer monsoon gyre is associated with the eastward extension of the Asian summer monsoon trough, which creates a favorable condition for cyclogenesis, so tropical cyclones and typhoons dominate the WNP-EA region

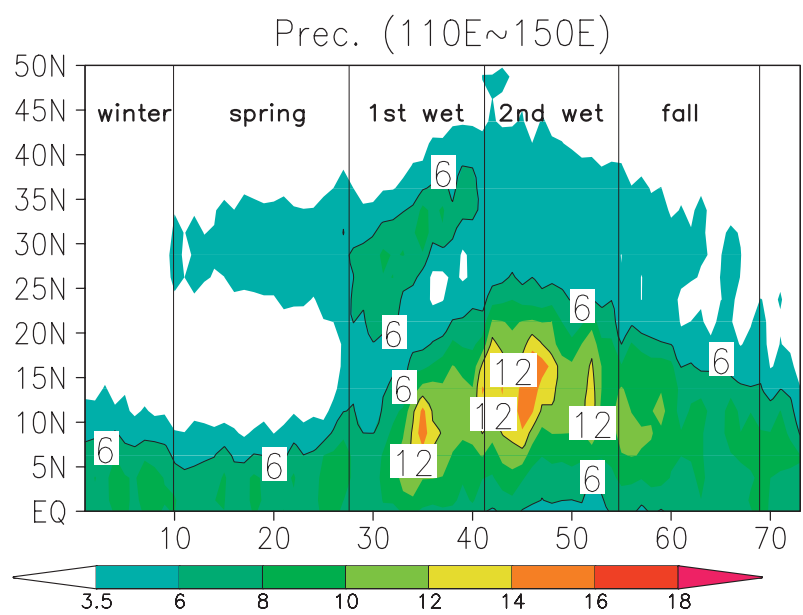

FIG. 1. The CMAP seasonal precipitation climatology (1979-2006) averaged over $110^{\circ}-150^{\circ} \mathrm{E}$

during this period. Late in September (the 55th pentad), cold and dry air associated with the continental high starts to move southward into the WNP-EA region. The tropical convection is also weakened and retreats southward, which signals the start of the fall period, when a frontal system dominates the northern part of the WNP-EA region, while tropical convection (greater than $6 \mathrm{~mm}$ day $^{-1}$ ) dominates the southern part of the WNP-EA region. By the end of year, near the 68th pentad, the cold and dry northerly winter monsoon circulation dominates the entire WNP-EA region, so the winter period is a dry season over this region. A detailed discussion of the five major rainy periods can be found in CHTTT.

The rainy systems over the WNP-EA region can be classified into two major categories: tropical convection over the south and frontal systems over the north. The rainfall associated with the frontal system, with a southwest-northeast tilting rainband, can be found in spring, the first wet period, fall, and winter (Figs. 2a, 2b, $2 \mathrm{~d}$, and $2 \mathrm{e}$ ). The tilting rainbands in the first wet period and fall are connected to tropical convection, while the tilting rainbands in spring and winter are not. This southwest-northeast tilting rainband is associated directly or indirectly with horizontal moisture convergence at low and midlevels (CHTTT). The major tropical convection over the WNP-EA region, on the other hand, can be found in the first and second wet periods and fall (Figs. 2b-d). Most of the rainfall from tropical convection is over oceanic regions, such as the South China Sea and the Philippine Sea. The tropical convection starts in the first wet period, reaches its maximum strength in the second wet period, when the Asian summer monsoon trough extends eastward, and retreats from north to south in fall. The tropical convection is 
(a) Spring (p10 p27)

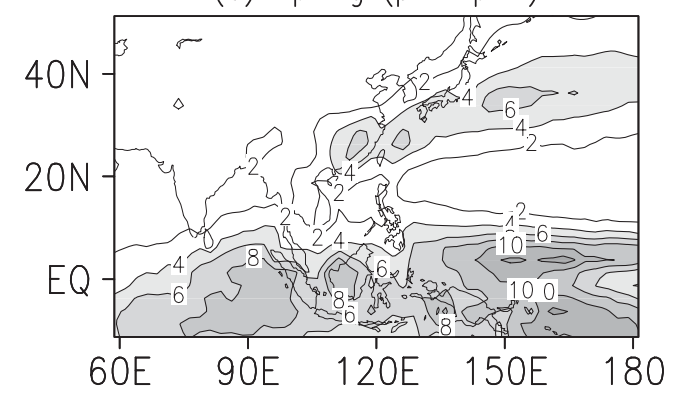

(c) 2 nd wet $(p 42 \sim p 54)$

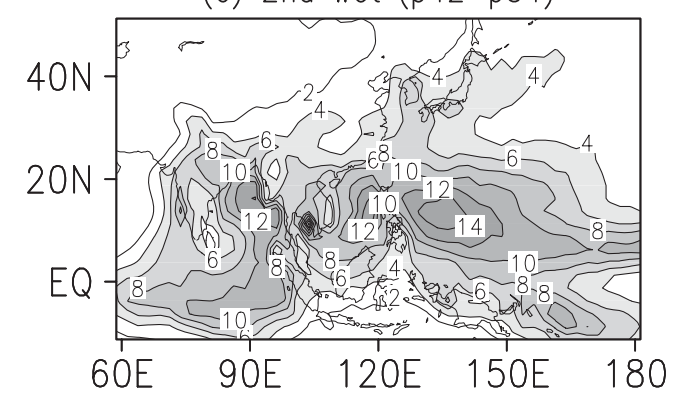

(e) Winter (p68 p9)

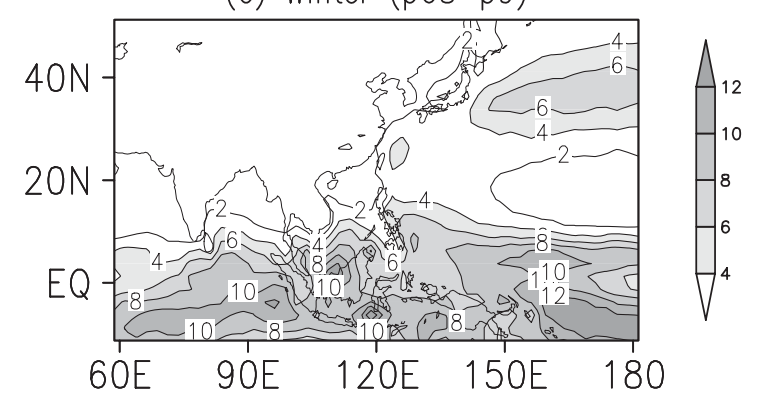

(b) 1 st wet (p28 p41)

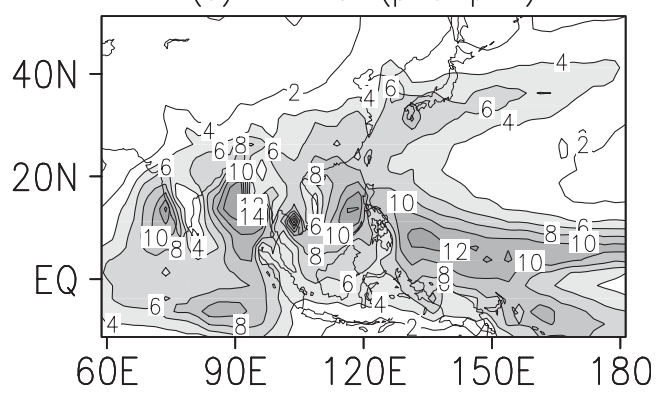

(d) Fall (p55 p67)

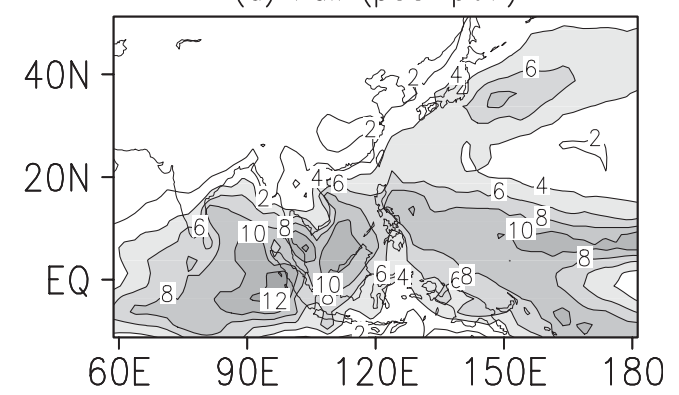

FIG. 2. Spatial distribution of the WNP-EA precipitation in the (a) spring period, (b) first wet period, (c) second wet period, (d) fall period, and (e) winter period. The contour interval is $2 \mathrm{~mm} \mathrm{day}^{-1}$.

most closely associated with local boundary conditions, such as SST and the net energy into the atmospheric column $F^{\text {net }}$, which is the sum of evaporation, sensible heat, and longwave and shortwave radiative fluxes, and their spatial distribution (CHTTT).

\section{b. Interannual variation}

Figure 3 shows precipitation anomalies averaged over $110^{\circ}-150^{\circ} \mathrm{E}$ for the three strongest $\mathrm{El}$ Niño events since 1979-the 1982-83, 1991-92, and 1997-98 El Niñosand their composite. A 2-yr period is shown from the El Niño growing year (0) to the El Niño decaying year (1). Over the north (north of $20^{\circ} \mathrm{N}$ ), positive precipitation anomalies are found between $25^{\circ}$ and $35^{\circ} \mathrm{N}$ in the period from the end of year 0 to April of year 1 and the period around June and July of year 1, which occur in all three El Niño events. This indicates that rainfall associated with frontal systems becomes larger in winter
(0-1), spring (1), and the first wet period (1). On one hand, because of the enhancement of rainfall in winter $(0-1)$, no clear dry (winter) season (68-82nd pentad) is found (Fig. 4a). On the other hand, the onset time of the spring rainy period (the straight line at the $83 \mathrm{rd}$ pentad in Fig. 4a) and the first wet period (at pentad 101 in Fig. $4 \mathrm{~b})$ does not change significantly even though the rainfall is increased in both periods of the El Niño decaying year.

Over the southern region (south of $20^{\circ} \mathrm{N}$ ), where rainfall is mainly associated with tropical convection, rainfall is first enhanced around the second wet period of year 0 , but is suddenly reduced in the fall of year 0 (Fig. 3). This reduced rainfall persists for almost one year into the second wet period of year 1. In other words, negative rainfall anomalies occur in fall (0), winter (0-1), spring (1), and the first and second wet periods (1). This rainfall variation also indicates a biennial variation 


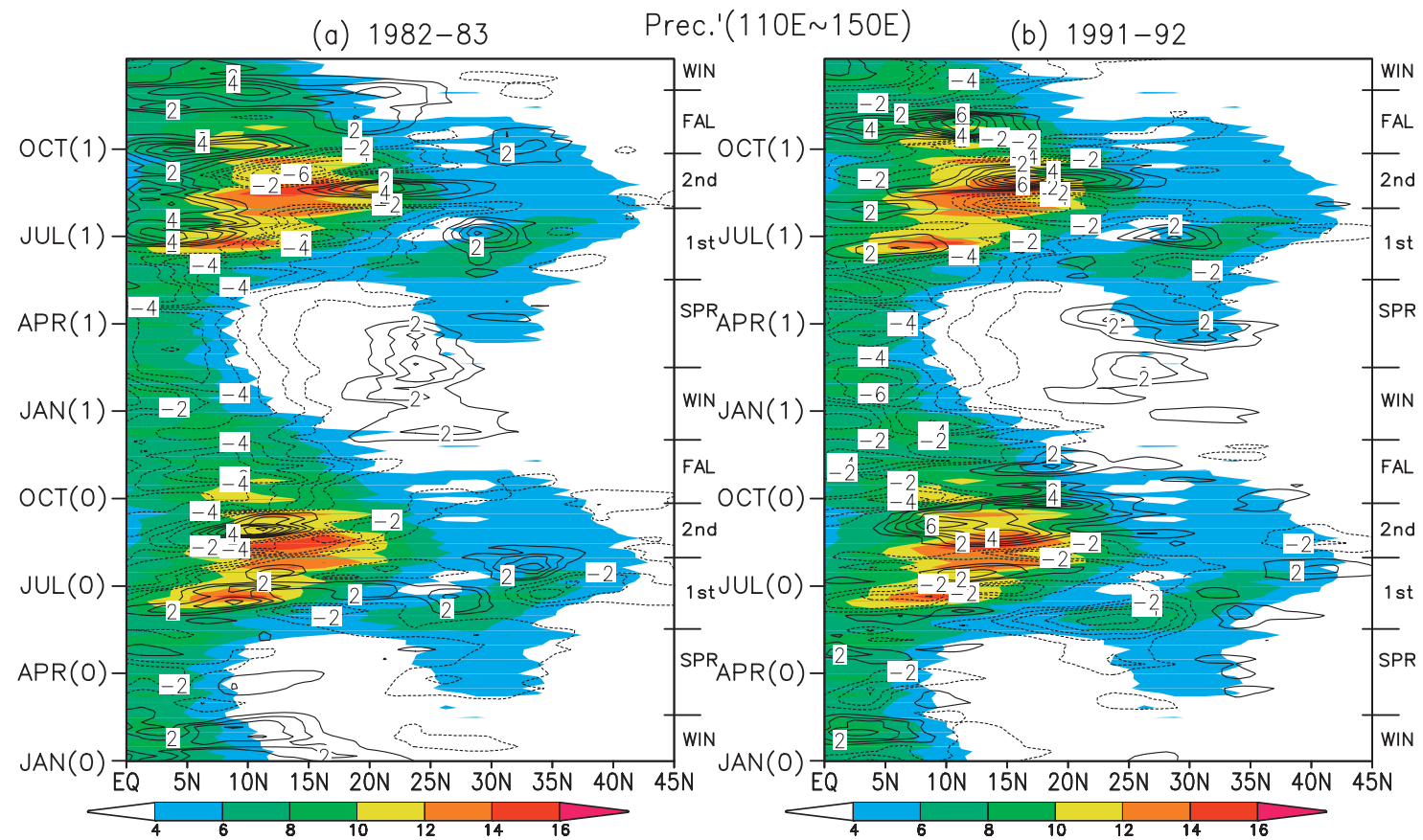

(c) $1997-98$

(d) Composite

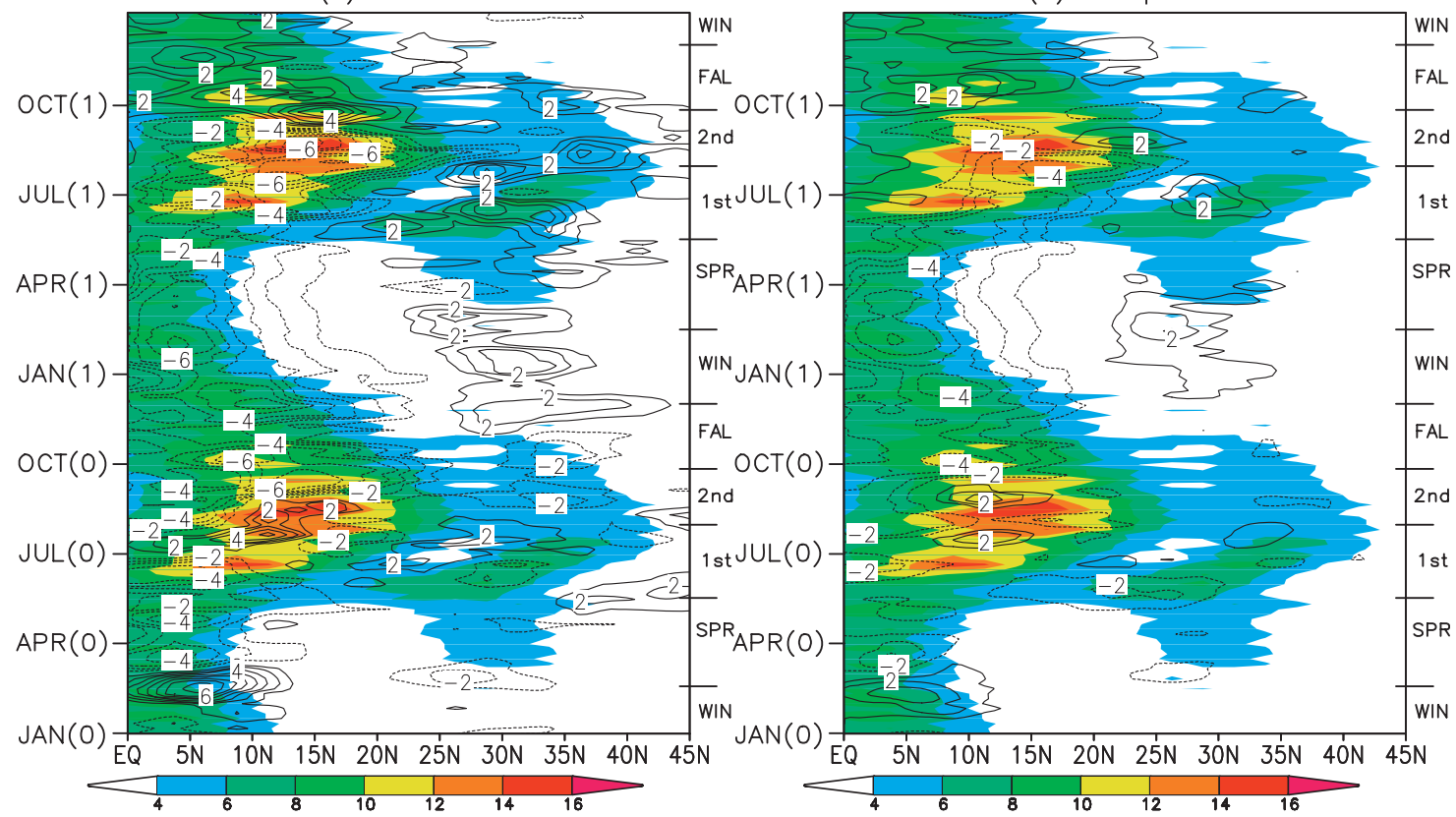

FIG. 3. Precipitation anomalies averaged over $110^{\circ}-150^{\circ} \mathrm{E}$ (contour) for (a) $1982-83$, (b) 1991-92, (c) 1997-98, and (d) composite of the three strong El Niño events. The contour interval is $1 \mathrm{~mm}$ day $^{-1}$. Shading is the precipitation climatology of the 2-yr period.

between the second wet periods of year 0 and year 1 . Upon closer examination, the positive (negative) rainfall anomalies in the second wet period of year 0 (year 1) are found to be associated with the change in intraseasonal variations, which is seen more clearly when examining each El Niño event (Figs. 3 and 4c). The association of the intraseasonal variation with El Niño has been discussed in Lau and Nath (2006) and Wang and Zhang (2002). The reversal of rainfall anomalies in the fall of year 0 occurs within only four pentads around the 50th, with the rainfall change from 15 to $5 \mathrm{~mm}^{\text {day }}{ }^{-1}$ (Fig. 4c). Further examination of the onset of each period reveals a 

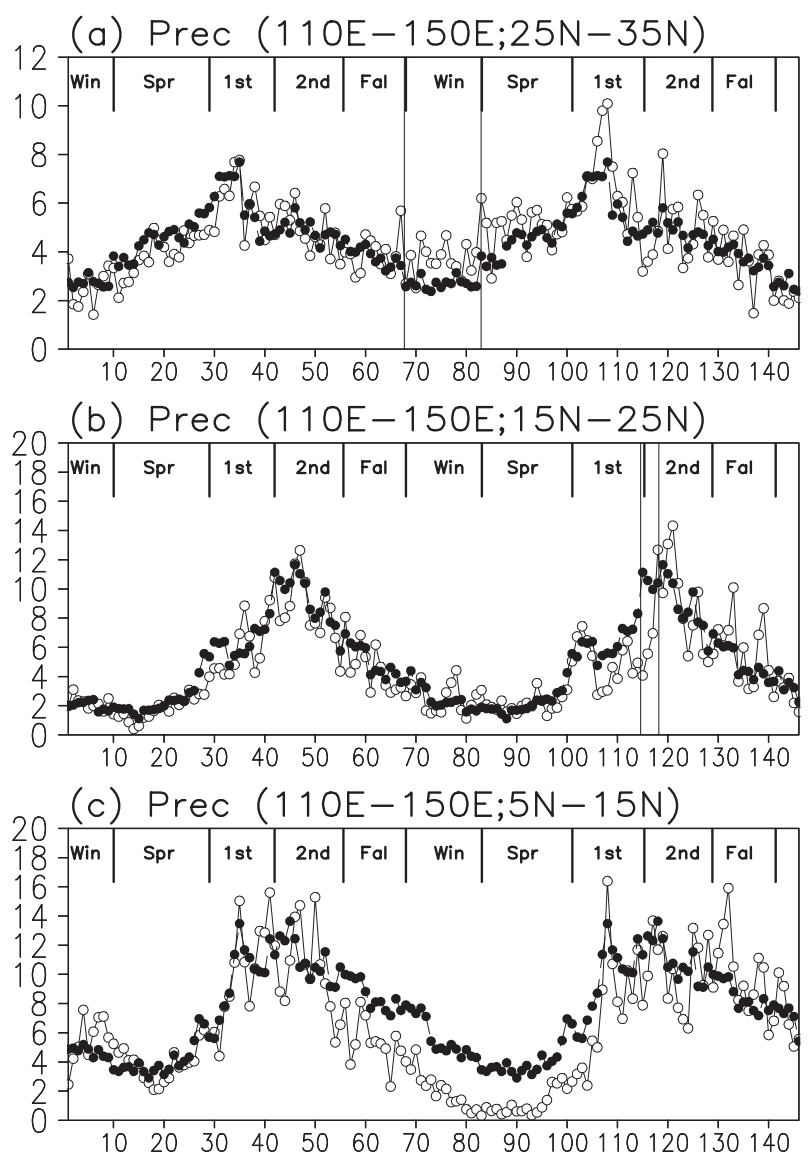

FIG. 4. Precipitation for the composite of the three strong El Niño events (hollow circles) and the climatology (solid circles) averaged over $110^{\circ}-150^{\circ} \mathrm{E}$ and (a) $25^{\circ}-35^{\circ} \mathrm{N}$, (b) $15^{\circ}-25^{\circ} \mathrm{N}$, and (c) $5^{\circ}-15^{\circ} \mathrm{N}$. The straight line in (a) is the onset of the winter $(0-1)$ and spring (1) rainy periods. The straight lines in (b) indicate the onset of the second wet period (1).

clear delay of onset for the second wet period of year 1 (Fig. 4b), while other rainy periods, such as the first wet period (0 and 1$)$ and the second wet period (0), do not show any clear sign in the change of onset. Overall, rainfall in the six rainy periods over the 2 -yr period is clearly associated with strong El Niño events as follows: the second wet period (0), fall (0), winter (0-1), spring (1), and the first and second wet periods (1). We will further discuss the association of the major rainy systems over the WNP-EA region with El Niño and possible mechanisms for inducing such rainfall anomalies in the following sections.

\section{The northern part of the WNP-EA sector}

\section{a. Spatial variation}

Figure 5 shows the rainfall anomalies in the four rainy periods that are dominated by the southwest-northeast tilting rainband over the northern part of the WNP-EA region, which could possibly have strong El Niño impacts, such as those shown in Fig. 3. During the first wet period (0), no clear anomalies occur for the pre-mei-yu/ mei-yu rainband (Fig. 5a), consistent with the results shown in Fig. 3. In winter (0-1), a significant rainfall enhancement occurs along the east coast of the Asian continent from southeastern China to the eastern part of Japan and coincides well with the major winter rainband that is associated with the frontal system (shaded area in Fig. 5b). In spring (1), similar positive precipitation anomalies are also found over southeastern China, Taiwan, and Japan, which are dominated by the southwest-northeast tilting spring rainband (shading in Fig. 5c). In the first wet period (1), relatively stronger positive precipitation anomalies (greater than $2 \mathrm{~mm} \mathrm{day}{ }^{-1}$ ) associated with the pre-mei-yu/mei-yu rainband occur from the East China Sea to the east of Japan. We further note that rainfall anomalies also occur over the southern part of the WNP-EA region for all four rainy periods, which will be discussed in the next section.

On a seasonal time scale, the southwest-northeast titling rainband over the northern part of the WNP-EA region is mainly induced by horizontal moisture convergence (CHTTT), which is associated with horizontal velocity. Thus, we first examine the horizontal moisture convergence in the lower troposphere (Fig. 6). Positive horizontal moisture convergence anomalies are clearly found along the east coast of the Asian continent in the winter (0-1), spring (1), and first wet (1) periods, which coincide well with the positive precipitation anomalies shown in Fig. 5. This implies that the precipitation changes on an interannual time scale are also associated with horizontal moisture convergence in the low and mid troposphere. This positive horizontal moisture convergence is mainly induced by the low-level anticyclonic circulation anomaly over the Philippine Sea and the western North Pacific, which is a well-known feature associated with El Niño (e.g., Chang et al. 2000a,b; Chen et al. 1992; Chen et al. 2007; Chou et al. 2003; Chou 2004; Huang and Sun 1992; Kawamura et al. 2001; Lau and Bua 1998; Lau et al. 2000; Lau and Wu 2001; Lau and Nath 2000, 2006; Nitta 1987; Tanaka 1997; Wang et al. 2000; Wang et al. 2001; Wang and Zhang 2002; Weng et al. 1999; Wu and Wang 2000). The component of the anomalous horizontal moisture convergence associated with anomalous moisture, on the other hand, is relatively weak. During the mature phase of El Niño in winter (0-1), the corresponding low-level anticyclonic circulation anomaly is strongest, so the positive horizontal moisture convergence anomalies are the largest and most widespread. However, the corresponding 
(a) 1 st wet (0)
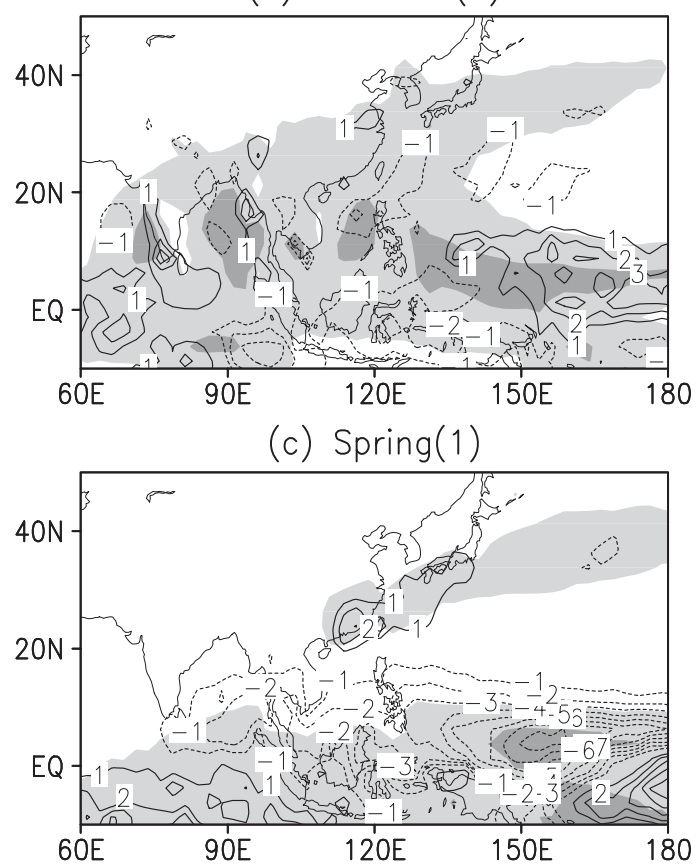

(b) Winter $(0-1)$

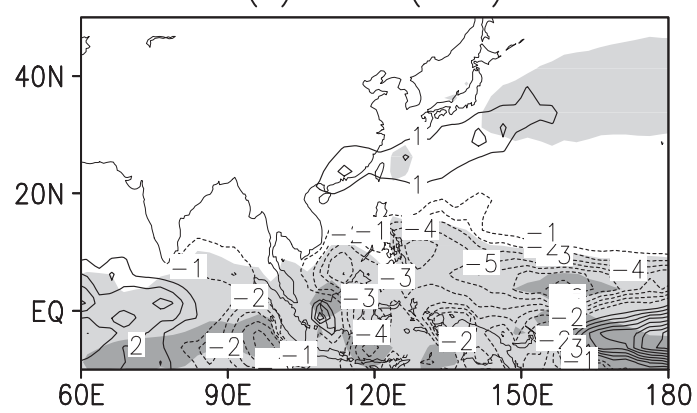

(d) 1 st wet (1)

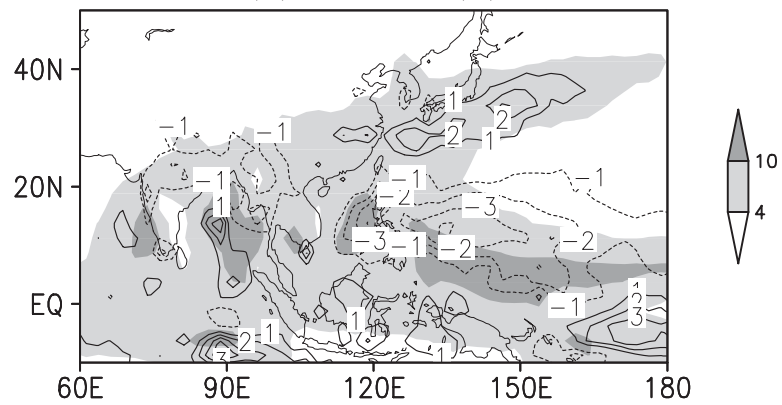

FIG. 5. Composite of the precipitation anomalies in (a) the first wet period of year 0 , (b) the winter period from year 0 to year 1 , (c) the spring of year 1 , and (d) the first wet period of year 1 . The contour interval is $1 \mathrm{~mm} \mathrm{day}^{-1}$. Shading is the climatology of precipitation: dark shading is over $10 \mathrm{~mm} \mathrm{day}{ }^{-1}$ and light shading between 4 and $10 \mathrm{~mm} \mathrm{day}^{-1}$.

positive precipitation anomalies are not the largest because it is in the driest season over the region. As the low-level anticyclonic circulation anomaly decays and shrinks seasonally, the horizontal moisture convergence anomalies are also weakened.

In the first wet period (0), a low-level cyclonic circulation anomaly associated with El Niño is found over the WNP-EA region, but it is relatively weaker and is concentrated only over the region of $0^{\circ}-15^{\circ} \mathrm{N}, 130^{\circ}-$ $170^{\circ} \mathrm{E}$ - away from the location of the pre-mei-yu/meiyu rainband. Thus, no clear horizontal moisture convergence anomalies nor their corresponding precipitation anomalies are found. We note that small positive horizontal moisture convergence anomalies-associated with a low-level anticyclonic circulation anomaly north of the cyclonic circulation anomaly over the region of $0-15^{\circ} \mathrm{N}, 130^{\circ}-170^{\circ} \mathrm{E}$ - can still be found over eastern Japan. This dipole pattern of the low-level circulation anomalies is commonly found over the WNP-EA region (e.g., Chou et al. 2003; Hsu and Lin 2007; Lau and Weng 2001; Tian and Yasunari 1992; Weng et al. 1999).

\section{b. Temporal variation}

In Fig. 7a, major positive horizontal moisture convergence anomalies are found from November of year 0 to July of year 1, with a short break in May of year 1 . The positive horizontal moisture convergence anoma- lies appear abruptly and extend broadly from $15^{\circ}$ to $35^{\circ} \mathrm{N}$ around November (0). Those anomalies coincide well with the positive precipitation anomalies in the winter (0-1), spring (1), and first wet (1) periods, which are relatively narrower in the meridional direction (shading in Fig. 7a). This is further evidence that the positive rainfall anomalies over the northern part of the WNP-EA region are associated with anomalous horizontal moisture convergence. Further examination of the variation of total horizontal moisture convergence (Fig. $7 \mathrm{~b}$ ) reveals that the positive horizontal moisture convergence during El Niño starts in March, identical to the starting time of the positive horizontal moisture convergence climatology, a sign for the onset of the spring rainy period (CHTTT). This implies that El Niño does not modify the onset of the spring rainy period (1), consistent with the result shown in Fig. 4a, even though the horizontal moisture convergence is enhanced greatly.

\section{The southern part of the WNP-EA sector \\ a. Spatial variation}

Most precipitation changes over the southern part of the WNP-EA region during El Niño occur in the second wet periods of year 0 and year1 and the fall of year 0 (Fig. 8), which will be the primary focus in this section. 
(a) 1st wet (0)

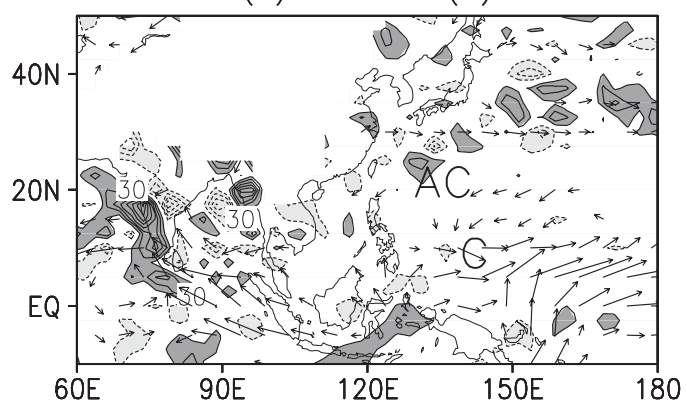

(c) Spring (1)

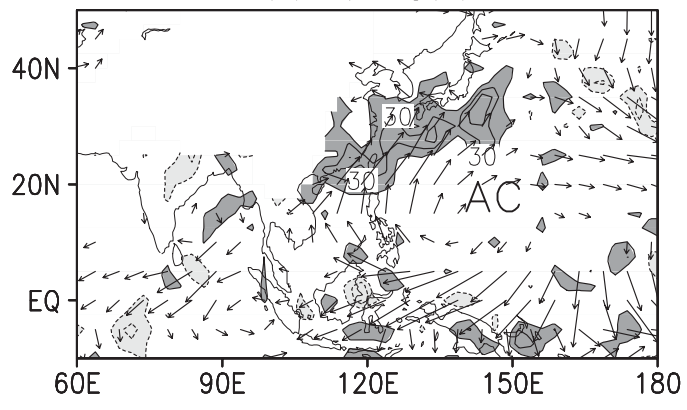

(b) Winter $(0-1)$

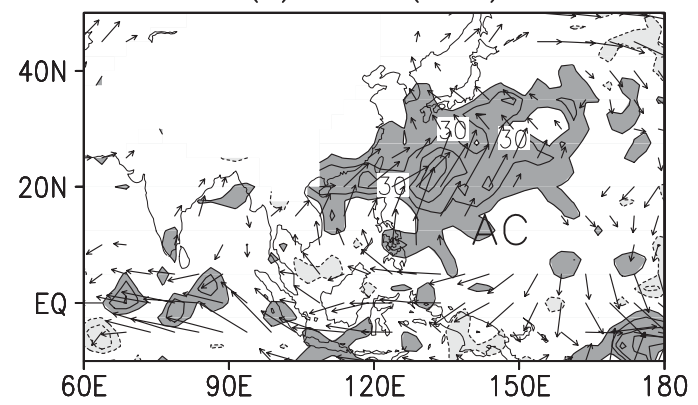

(d) 1 st wet (1)

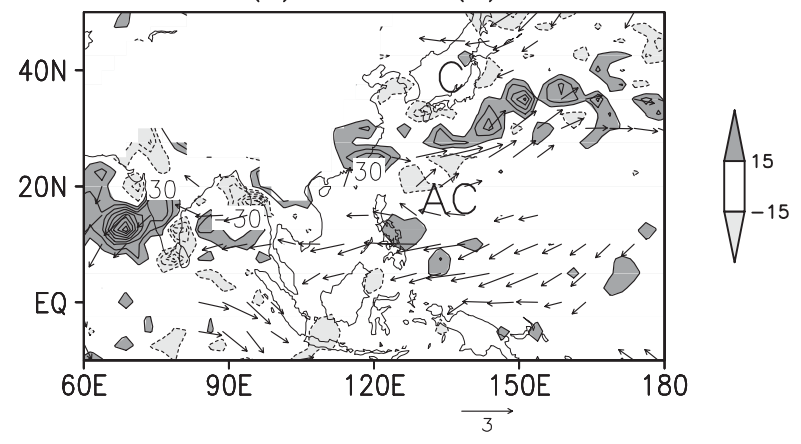

FIG. 6. As in Fig. 5 but for the low-level (1000-700 hPa) horizontal moisture convergence anomalies (contour) and the $925-\mathrm{hPa}$ wind anomalies (vector). The contour interval is $15 \mathrm{~W} \mathrm{~m}^{-2}$.

We also note that rainfall anomalies over the southern part of the WNP-EA region can also be found in other rainy periods, such as the four periods shown in Fig. 5, which will also be briefly discussed.

\section{1) THE SECOND WET PERIOD OF YEAR 0}

During the second wet period (0) most positive precipitation anomalies occur east of $140^{\circ} \mathrm{E}$ (Fig. 8a) and connect to the main positive precipitation anomalies over the equatorial eastern Pacific induced by the El Niño warm SST anomalies (not shown). The positive precipitation anomalies east of the major Asian summer monsoon gyre indicate an eastward extension of the Asian summer monsoon gyre and an eastward deepening of the Asian summer monsoon trough.

This eastward extension of the Asian summer monsoon trough will affect typhoon activity, such as the track (Wang and Chan 2002). The positive precipitation anomalies concur well with a low-level cyclonic circulation anomaly (Fig. 8b), commonly found in the summer of the El Niño growing year (e.g., Chou et al. 2003; Wang and Zhang 2002; Wu et al. 2003). Negative precipitation anomalies also occur over the Maritime Continent and the eastern Indian Ocean where lowlevel divergence anomalies are found. Since our interest is the WNP-EA region, we will focus on the positive precipitation anomalies in the following discussion.
The positive precipitation anomalies over the WNP may be associated with the Asian summer monsoon gyre, which has a close relationship with the net energy flux into the atmosphere $F^{\text {net }}$ (CHTTT), so we first examine $F^{\text {net }}$ to understand possible mechanisms that can induce the precipitation anomalies over this region. Over the WNP where precipitation anomalies are positive, $F^{\text {net }}$ anomalies are also positive (Fig. 9a), which indicates that the atmosphere over this region is warmed by the net energy input. Unlike the positive precipitation anomalies, the positive $F^{\text {net }}$ anomalies are specific to the WNP region and do not link to the positive $F^{\text {net }}$ anomalies over the equatorial eastern Pacific (not shown). This warming effect enhances convection, so the corresponding precipitation is increased. Further examination of each component of $F^{\text {net }}$ reveals that the positive $F^{\text {net }}$ anomalies are mainly associated with positive surface heat flux anomalies into the atmosphere (Fig. 9b). Net surface heat flux is the sum of evaporation and sensible heat fluxes and surface solar and longwave radiation. Since surface longwave radiation tends to reduce the net surface heat flux into the atmosphere due to increased clouds induced by enhanced convection, surface longwave radiation cannot be responsible for the positive surface heat flux anomalies. The increased clouds attenuate insolation, so downward solar radiation is reduced (Fig. 9c), which does have a positive 
(a) $-v d q^{\prime}$

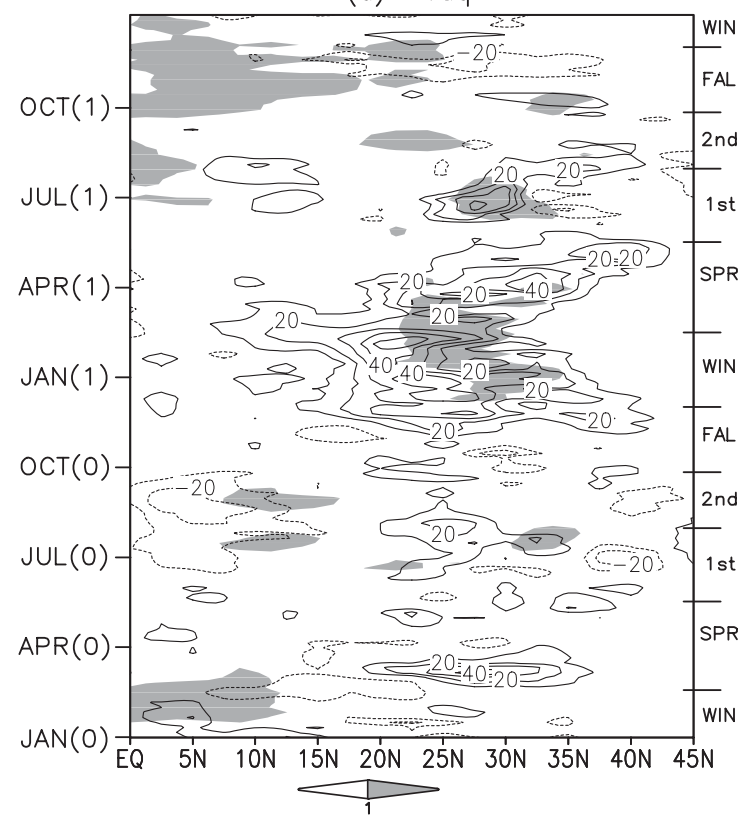

(b) $-v d q$

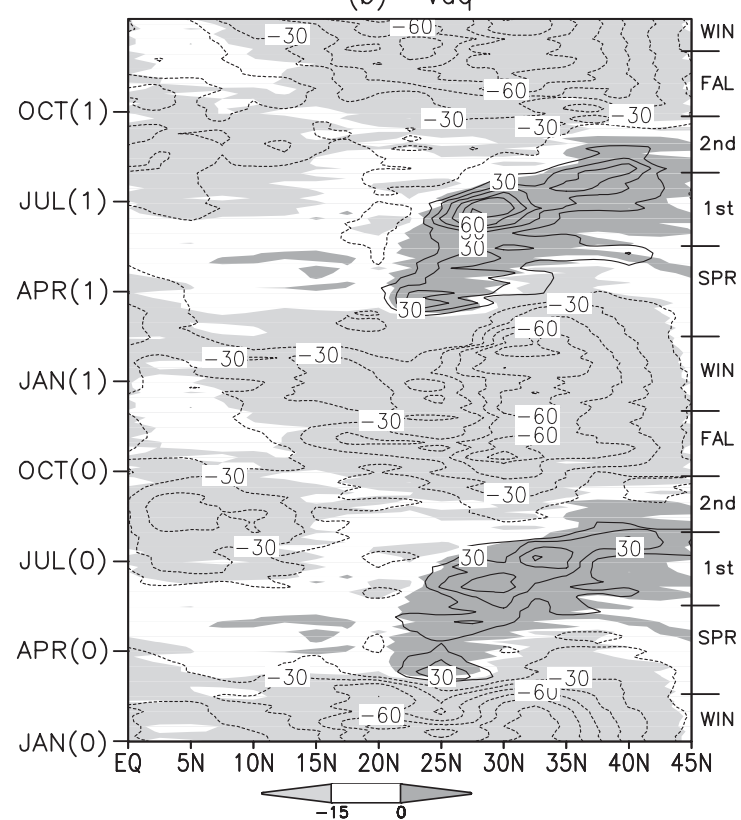

FIG. 7. Temporal variations of (a) the composite for the low-level (1000-700 hPa) horizontal moisture convergence anomalies (contour), with shading for the precipitation anomalies larger than $1 \mathrm{~mm} \mathrm{day}^{-1}$, and (b) the total low-level (1000$700 \mathrm{hPa}$ ) horizontal moisture convergence for the composite of the three strong El Niño events (contour) and climatology (shading).

contribution to the surface heat flux into the atmosphere. However, the net solar absorption by the atmosphere does not vary too much with clouds (Fig. 9d), so solar radiation is not a factor for the positive $F^{\text {net }}$ anomalies either. The sensible heat anomalies are also relatively small in this region (not shown). Thus, positive evaporation anomalies shown in Fig. 9e are the main source for the positive net surface heat flux anomalies, which are associated with the positive $F^{\text {net }}$ anomalies.

We next examine the processes for inducing these positive evaporation anomalies. Evaporation mainly depends on surface wind speed and the difference between atmospheric water vapor and saturated moisture at the ocean surface, which is sensitive to SST. Over the region with the positive $F^{\text {net }}$ anomalies, SST anomalies are negative (Fig. 9f), so the corresponding moisture difference is usually reduced. Thus, the positive evaporation anomalies cannot be induced by the cold SST anomalies. In other words, they must be associated with positive surface wind speed anomalies. Figure $8 \mathrm{~b}$ confirms that the near-surface wind speed over this region is increased, so the positive evaporation anomalies are associated with positive wind speed anomalies. In the second wet period (0), the Asian summer monsoon trough dominates the WNP, so the low-level cyclonic circulation anomaly over this region (Fig. 8b), which is induced by El Niño, implies an increase in near-surface wind speed, which enhances evaporation. Thus, the corresponding precipitation can be increased directly due to an increase in the atmospheric moisture via evaporation processes. The increased evaporation then warms the atmosphere via a convection process, that is, positive $F^{\text {net }}$ anomalies, so convection is enhanced and, thus, precipitation increased. This is a dynamic feedback due to the change in the convection-related circulation. Both enhanced evaporation and increased clouds can reduce SST, so the ocean here, with negative SST anomalies, is just a simple response to the atmospheric forcings, not a forcing for the atmosphere, which has been discussed in many studies, particularly over the WNP (e.g., Wang et al. 2005; Wu et al. 2006; Wu and Kirtman 2007).

\section{2) SECOND WET PERIOD OF YEAR 1}

During the second wet period of year 1, the anomalies are reversed (Figs. $8 \mathrm{c}$ and $8 \mathrm{~d}$ ), compared to the second wet period of year 0 (Figs. $8 \mathrm{a}$ and $8 \mathrm{~b}$ ). Negative precipitation anomalies occur over the South China Sea, the Philippine Sea, and the WNP, which implies a weakening of the Asian summer monsoon gyre and the Asian summer monsoon trough. Similar to the second wet period of year 0 in which the precipitation anomalies are related to a low-level circulation anomaly, the 
(a) 2nd wet (0)

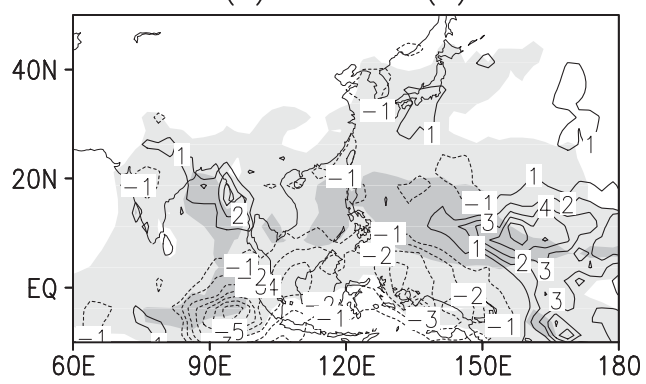

(c) 2nd wet (1)

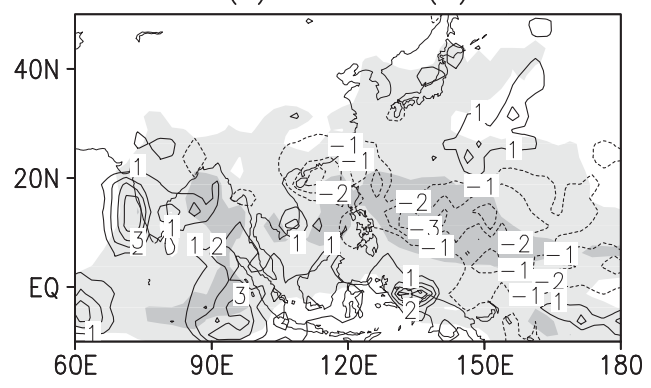

(e) Fall (0)

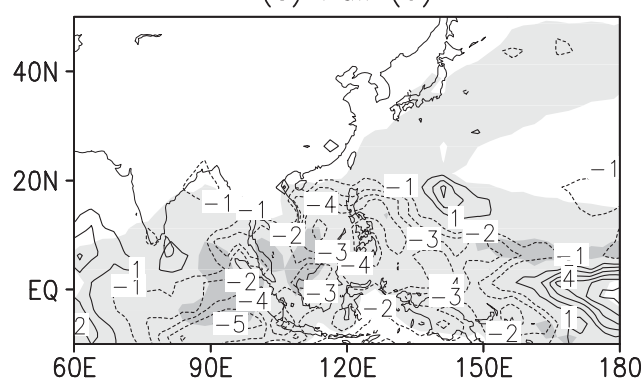

(b) 2nd wet (0)

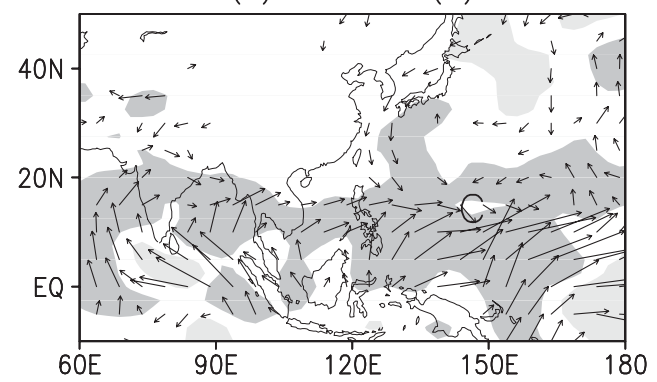

(d) 2nd wet (1)

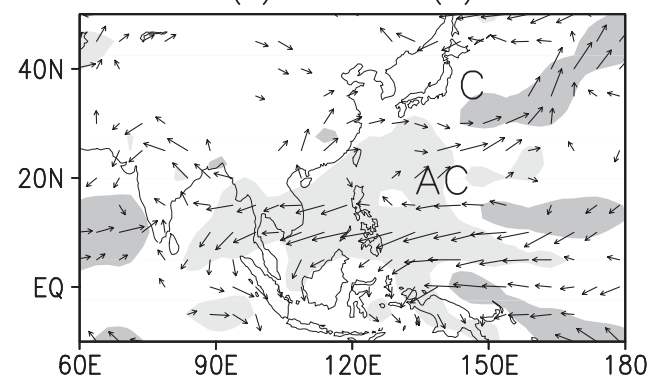

(f) Fall (0)

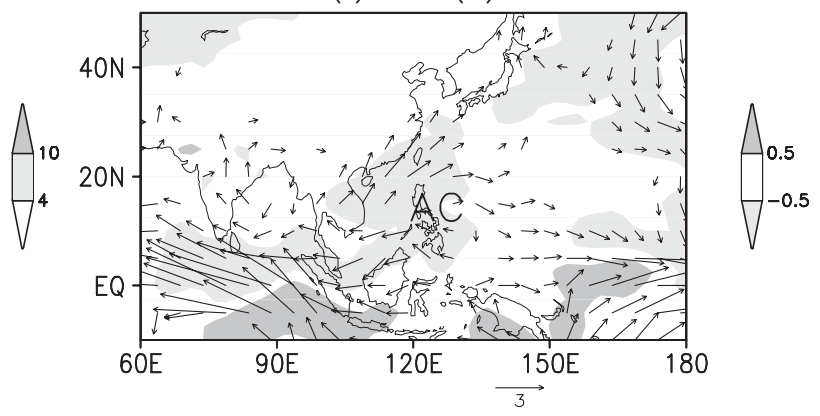

FIG. 8. Composite of the precipitation anomalies (contour) for (a) the second wet period of year 0, (c) the second wet period of year 1 , and (e) the fall of year 0 , with shading for climatology. The composite of the 925-hPa wind anomalies (vector) for (b) the second wet period of year 0 , (d) the second wet period of year 1 , and (f) the fall of year 0 . The dark shading is for wind speed anomalies greater than $0.5 \mathrm{~m} \mathrm{~s}^{-1}$ and the light shading is for wind speed anomalies less than $-0.5 \mathrm{~m} \mathrm{~s}^{-1}$.

negative precipitation anomalies are associated with an anticyclonic circulation anomaly. However, both the precipitation anomalies and the low-level anticyclonic circulation anomaly are located much farther westward than those in the second wet period of year 0 . A clear cyclonic circulation anomaly is also found in the region $30^{\circ}-45^{\circ} \mathrm{N}, 120^{\circ}-160^{\circ} \mathrm{E}$ north of the anticyclonic circulation anomaly and the negative precipitation anomalies in the WNP. Corresponding to the cyclonic circulation anomaly, positive but weak precipitation anomalies are found. This dipole pattern has been discussed in several studies (e.g., Chou et al. 2003; Hsu and Lin 2007; Lau and Weng 2001; Tian and Yasunari 1992; Weng et al. 1999). Positive precipitation anomalies are also found over the Maritime Continent and the eastern Indian Ocean, with opposite signs to those in the second wet period of year 0 . This reversal of the anomalies in the second wet periods between year 0 and year 1 indicates a biennial variation over the WNP-EA region that is associated with El Niño, similar to the result shown in Fig. 3; however, the locations of these anomalies are slightly different between these two second wet periods.

Examining the heat fluxes over the WNP with negative precipitation anomalies, $F^{\text {net }}$ anomalies are negative (Fig. 10a), which is mainly due to negative surface heat flux anomalies (Fig. 10b). Even though the decreased clouds can allow more insolation to penetrate through the atmosphere and reach the ocean surface (Fig. 10c), the net solar absorption by the atmosphere is still relatively weak (Fig. 10d). Thus, negative evaporation anomalies, shown in Fig. 10e, are the main contributor to the negative $F^{\text {net }}$ anomalies via surface heat 
2nd wet (0)

(a) Fnet'

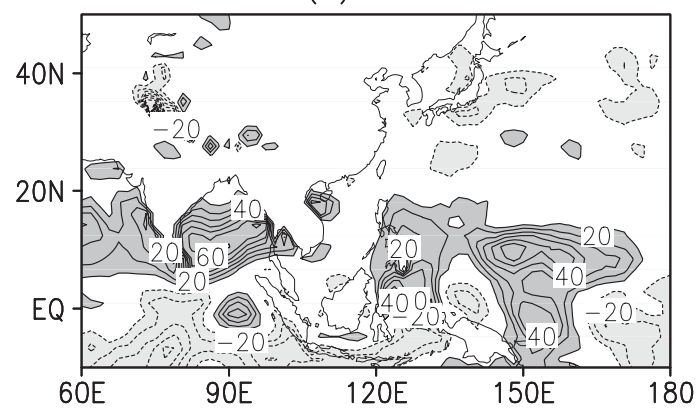

(c) FSWs'

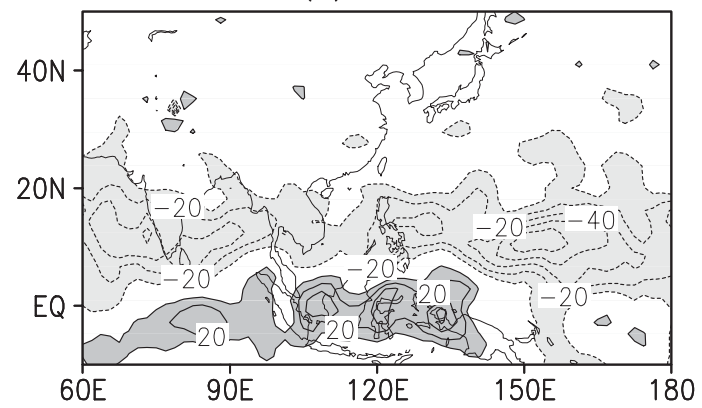

(e) $E^{\prime}$

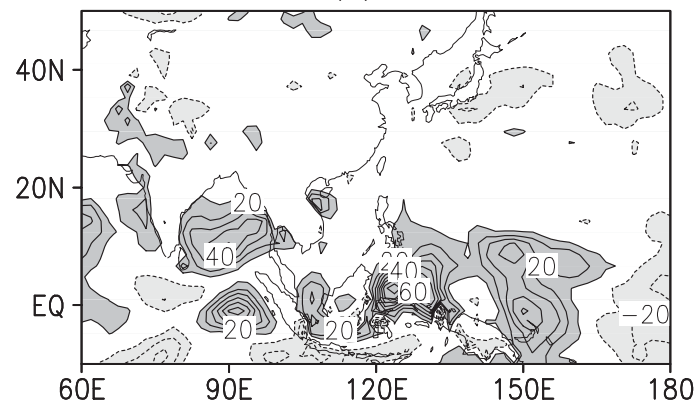

(b) $\mathrm{Fs}^{\prime}$

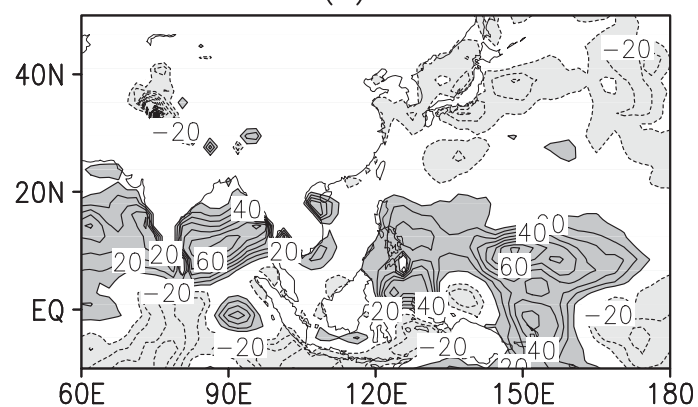

(d) FSW'

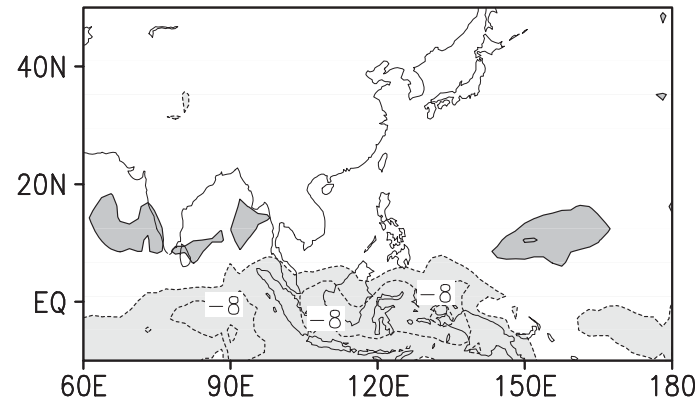

(f) SST'

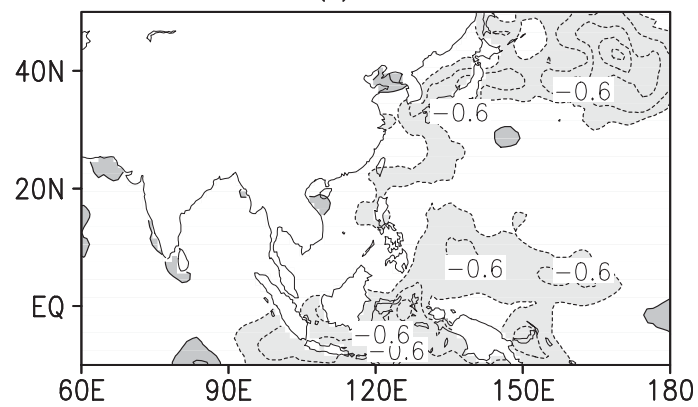

FIG. 9. Composite of the anomalies in the second wet period of year 0 for (a) the net energy into the atmospheric column, (b) the net surface heat flux, (c) the net solar radiation at surface, (d) the net solar radiation absorbed by the atmosphere, (e) evaporation, and (f) SST. Units for energy and heat flux are $\mathrm{W} \mathrm{m}^{-2}$.

flux exchange. These negative evaporation anomalies are mainly associated with reduced surface wind speed (Fig. 8d) since the corresponding positive SST anomalies cannot induce such evaporation anomalies (Fig. 10f). The surface wind speed is reduced because of the low-level anticyclonic circulation anomaly coinciding with the Asian summer monsoon trough, which is associated with El Niño. Similar to those of the second wet period of year 0, the warm SST anomalies are also associated with evaporation and solar radiation anomalies: weaker evaporation and stronger downward solar radiation because of less cloud. The positive SST anomalies are located farther westward in year 1 than in year 0 , which coincides well with the corresponding precipita- tion anomalies. Overall, the changes of the heat fluxes and SST shown in Fig. 10 are roughly opposite to those in Fig. 9.

\section{3) FALl OF YeAR 0}

In the fall of year 0 (Fig. 8e) clear negative precipitation anomalies occur over the southern oceans, including the eastern Indian Ocean, the South China Sea, the Philippine Sea, and the Maritime Continent. This indicates a weakening of tropical convection, which is a main process for the fall rainfall in the southern part of the WNP-EA region. An anticyclonic circulation anomaly is found over the South China Sea and the Philippine Sea that coincides well with the negative 
2nd wet (1)

(a) Fnet'

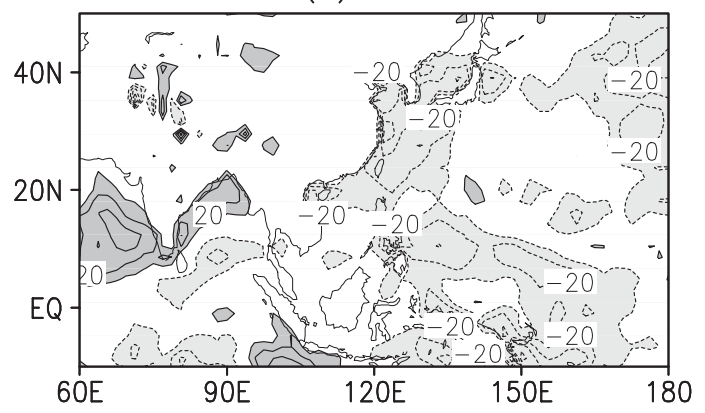

(c) FSWs'

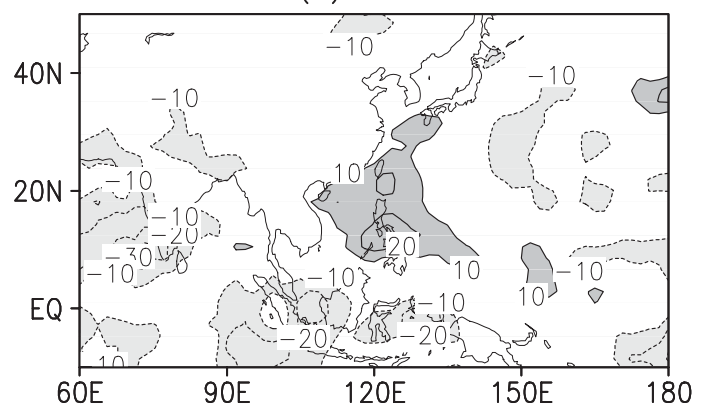

(e) $E^{\prime}$

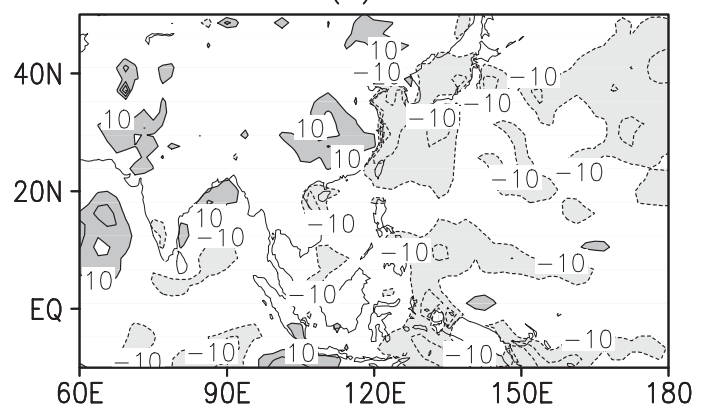

(b) $F s^{\prime}$

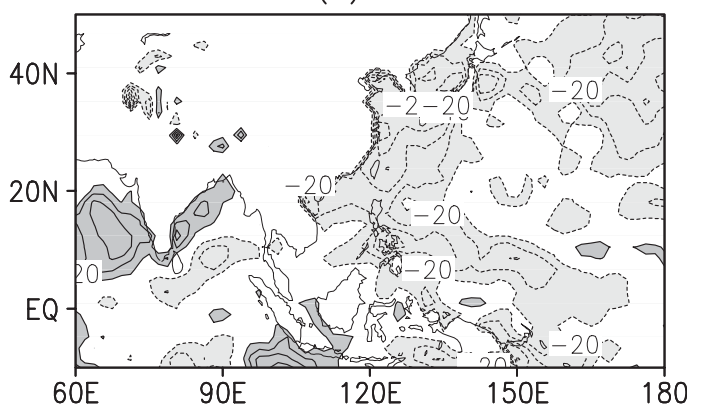

(d) FSW'

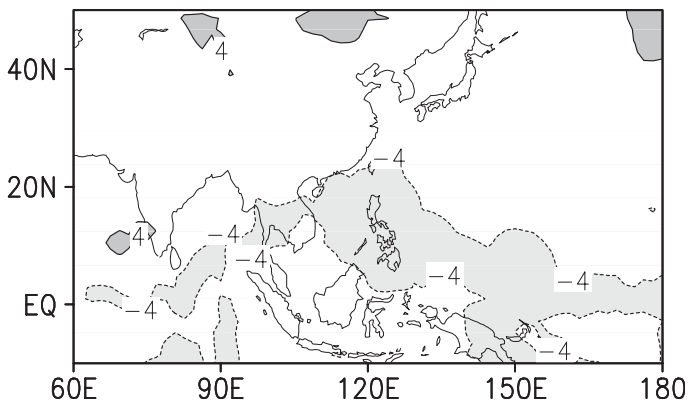

( $f$ ) SST'

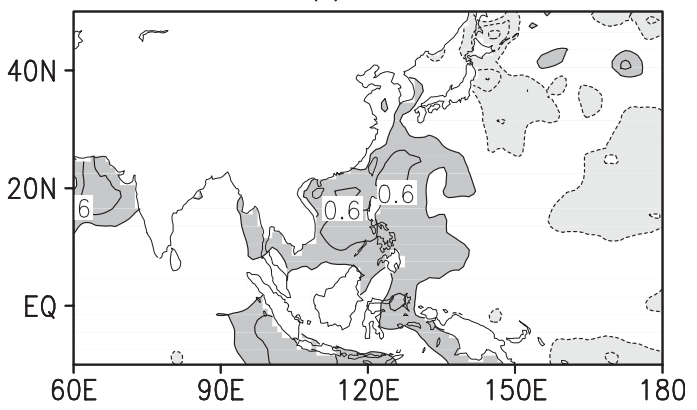

FIG. 10. As in Fig. 9 but for the second wet period of year 1.

precipitation anomalies. Anomalous divergence is also found centered over the Maritime Continent (Fig. 8f) consistent with a weakening of the Walker circulation during El Niño.

Over the southern part of the WNP-EA, which is still dominated by tropical convection, $F^{\text {net }}$ anomalies are negative (Fig. 11a), so the corresponding convection is reduced. Similar to the processes in the two wet periods, the negative $F^{\text {net }}$ anomalies are mainly associated with negative evaporation anomalies in convective regions. Unlike the second wet period (0), during the last period the corresponding wind speed anomalies are no longer positive but become slightly negative (Fig. 8f). The corresponding SST anomalies, on the other hand, are still negative and cover relatively broader regions (Fig. 11b) compared to those of the second wet period (0). Thus, both reduced wind speed and cold SST anomalies contribute to the negative evaporation anomalies. The negative SST anomalies here cannot be induced by solar radiation, such as in the second wet period (0 and 1$)$, since convection is weaker and the corresponding clouds are decreased, which should allow more insolation to reach the ocean surface. Several studies indicate that ocean dynamics may be responsible for these cold SST anomalies (e.g., Chou et al. 2004; Su et al. 2001).

\section{4) OTHER RAINY PERIODS}

In both the winter (0-1) and spring (1) periods, strong negative precipitation anomalies occur over the equatorial western Pacific warm pool region (Figs. 5b and 5c), 
Fall (0)
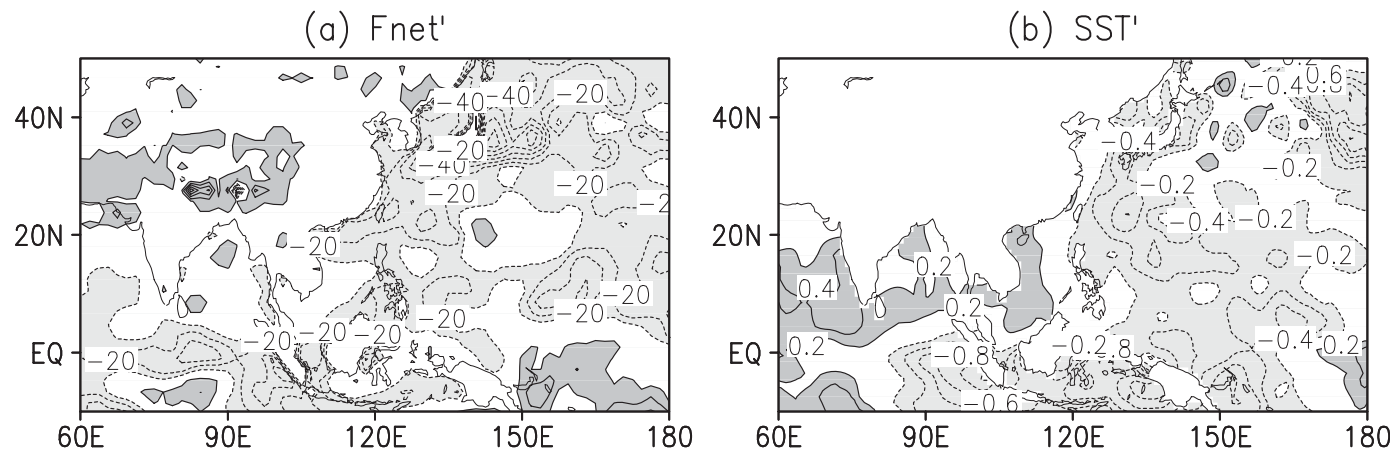

FIG. 11. Composite of the anomalies in the fall of year 0 for (a) the net energy into the atmospheric column and (b) SST.

which is a part of the well-known horseshoe pattern that is associated with an El Niño event (Ropelewski and Halpert 1987). Reversal signs of precipitation anomalies are found between the first wet periods of year 0 and year 1: positive anomalies in year 0 and negative anomalies in year 1 (Figs. 5a and 5d). In year 0 most positive precipitation anomalies are located east of $150^{\circ} \mathrm{E}$, slightly more southeastward than in the second wet period (0). These positive precipitation anomalies coincide well with the cyclonic circulation anomaly shown in Fig. 6a. In year 1, on the other hand, the negative precipitation anomalies extend much more westward to the South China Sea and farther northward to around $20^{\circ} \mathrm{N}$. The negative precipitation anomalies also coincide well with the anticyclonic circulation anomaly shown in Fig. 6d. In this rainy period, clear dipole patterns of the precipitation and low-level wind anomalies are found over the WNP-EA region: negative precipitation anomalies and an anticyclonic circulation anomaly associated with tropical convection in the south, and positive precipitation anomalies and a cyclonic circulation anomaly associated with the premei-yu/mei-yu rainband in the north. The biennial variations of the precipitation anomalies and low-level circulation anomalies in the first wet periods between year 0 and year 1 are similar to those found in the second wet periods (Fig. 8).

In winter (0-1) and spring (1), the peak phase of $\mathrm{El}$ Niño, negative precipitation anomalies are associated with either a weakening of the Walker circulation induced by the warm SST anomalies over the equatorial eastern Pacific or the local cold SST anomalies, which induce negative evaporation and $F^{\text {net }}$ anomalies (e.g., Chou 2004; Chou et al. 2004; Su et al. 2001). In both first wet periods of year 0 and year 1 , the precipitation and $F^{\text {net }}$ anomalies over the southern part of the WNP-EA region are similar to those in the second wet periods of the respective year so that the $F^{\text {net }}$ anomalies are a main source for the precipitation anomalies (not shown). However, the corresponding SST anomalies are quite different even though the corresponding evaporation anomalies are consistent with the $F^{\text {net }}$ anomalies. In year 0 the SST anomalies of the first wet period are slightly positive over the regions with positive precipitation and $F^{\text {net }}$ (evaporation) anomalies (not shown), but they are negative in the second wet period. In year 1 the signs of the anomalies are reversed. Thus, the SST anomalies have a slightly positive correlation with precipitation and $F^{\text {net }}$ in the two first wet periods, but have a negative correlation in the two second wet periods. In other words, the SST anomalies in the first wet period are forcing the precipitation anomalies. Besides the different SST anomalies, the contribution of near-surface wind speed is also weaker in the two first wet periods since the Asian summer monsoon trough has not yet extended eastward to the WNP region. Overall, the $F^{\text {net }}$ anomalies in the first wet periods of year 0 and year 1 are associated with evaporation anomalies that are determined by similar, but relatively weaker, contributions of the SST and wind speed anomalies.

\section{b. Temporal variation}

To understand the variation of those variables over the southern part of the WNP-EA region associated with El Niño, we further examine temporal variations of $F^{\text {net }}$, SST, and low-level wind anomalies (Fig. 12). The net energy into the atmosphere, $F^{\text {net }}$, is important to the precipitation over the southern part of the WNP-EA region, which is dominated by tropical circulation. Examining the regions south of $20^{\circ} \mathrm{N}$, positive $F^{\text {net }}$ anomalies appear around July (0) and abruptly change sign to negative values by the end of September (0) when the fall period starts. The negative $F^{\text {net }}$ anomalies then persist for one year to the end of September (1). The 
(a) Fnet

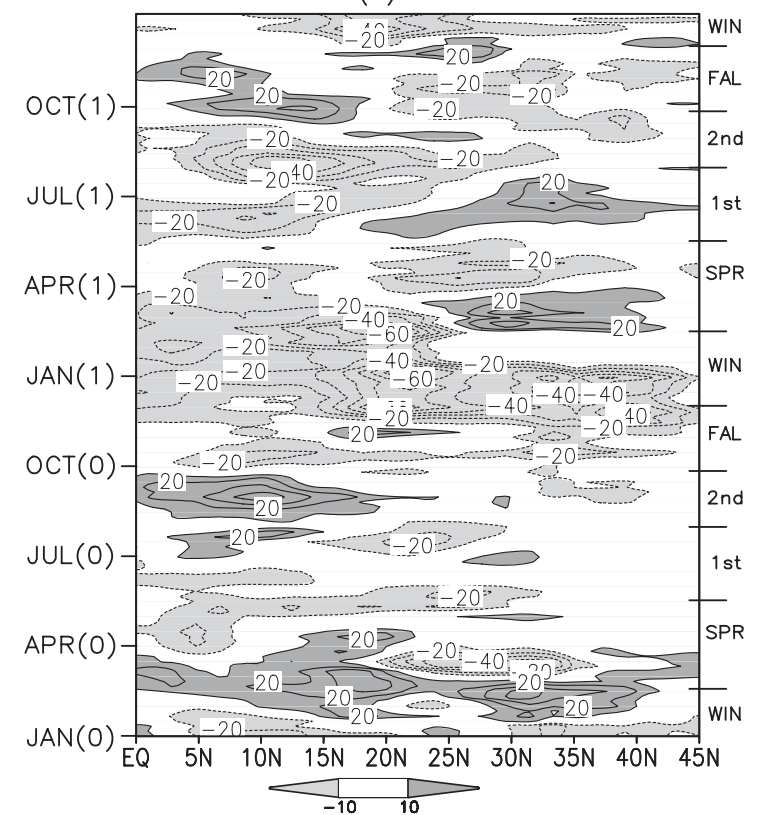

(c) $925 \mathrm{hPa} u^{\prime} \& \mathrm{v}$

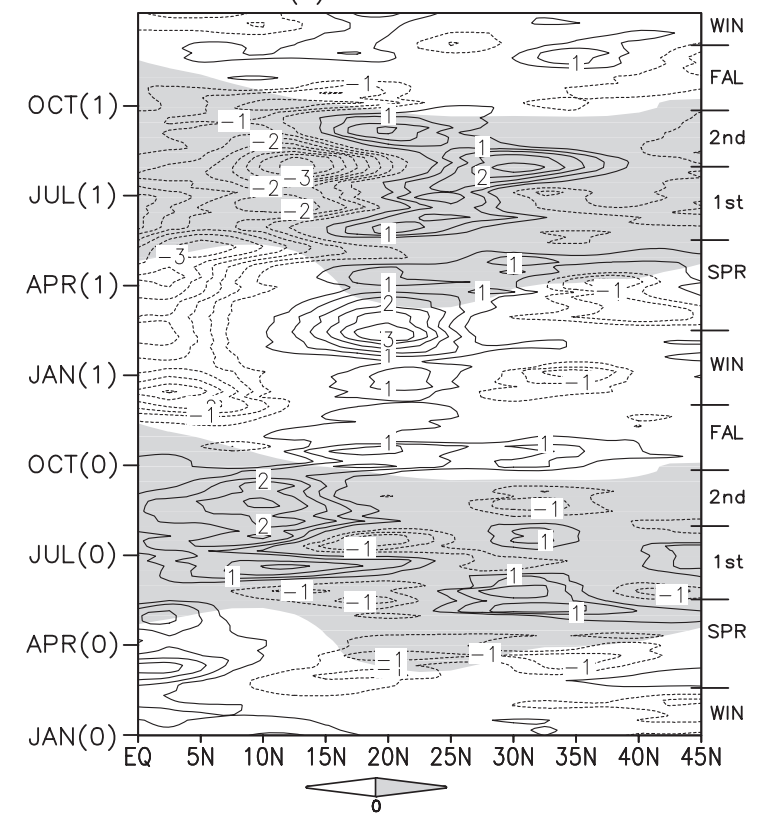

(b) SST'

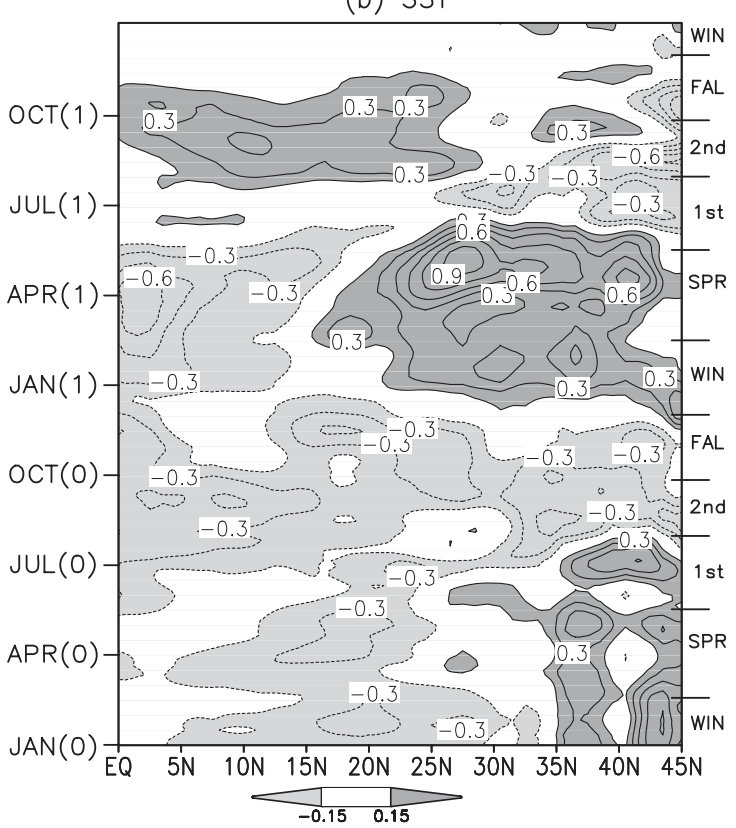

(d) $|\mathrm{V}| '(925 \mathrm{hPa})$

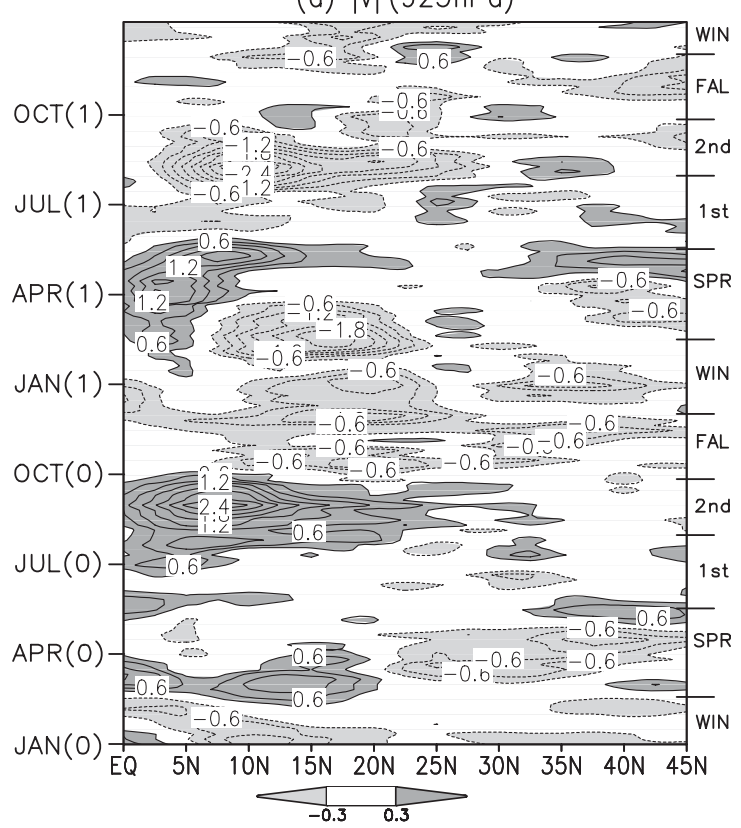

FIG. 12. Two-year temporal variations of the composite for the anomalies of (a) the net energy flux into the atmospheric column; (b) SST; (c) the $925-\mathrm{hPa}$ wind, with shading for the climatology of the negative meridional wind (southerly); and (d) the $925-\mathrm{hPa}$ wind speed averaged over $110^{\circ}-150^{\circ} \mathrm{E}$.

variation of $F^{\text {net }}$ is consistent with the variation of the precipitation anomalies over the southern part of the WNP-EA regions (Fig. 3d). This indicates a strong correlation between $F^{\text {net }}$ and the precipitation anomalies. The corresponding SST anomalies shown in Fig. $12 \mathrm{~b}$ have opposite signs to the $F^{\text {net }}$ anomalies during the second wet periods of year 0 and year 1 , but have the same sign as the $F^{\text {net }}$ anomalies (negative) from the beginning of October (0) to around June (1).

The SST anomalies have a relatively smooth variation in year 0 even though the $F^{\text {net }}$ anomalies have a sharp change in sign around the end of September (0). In year 1 , on other hand, the SST anomalies change sign around July (1), but the $F^{\text {net }}$ anomalies do not change their 
signs. Thus, the variation of the SST anomalies is different from the variation of both the $F^{\text {net }}$ anomalies and the precipitation anomalies over the southern part of the WNP-EA region in the second wet periods of year 0 and year 1 . In other words, the SST anomalies are not the main cause inducing the precipitation anomalies, particularly in the second wet periods of year 0 and year 1. This is different from the role of SST in creating mean precipitation in each rainy period.

Further examining of the low-level wind anomalies, a cyclonic circulation anomaly starts around June (0) and extends until the end of September (0). Low-level wind anomalies become anticyclonic when the mean circulation reverses from southerly to northerly, at the onset of the fall period (Fig. 12c), so this reversal of the lowlevel circulation anomalies is connected with seasonal variations (Chen et al. 2007; Chou 2004; Lau and Nath 2006; Wang and Zhang 2002). This anticyclonic circulation anomaly persists for one year until the end of September (1), a temporal variation similar to the $F^{\text {net }}$ and precipitation anomalies. This confirms that the lowlevel circulation anomaly plays a major role for inducing the precipitation anomalies. Figure $12 \mathrm{~d}$ shows the variation of the wind speed anomalies at $925 \mathrm{hPa}$. The wind speed anomalies show maximum (minimum) values in the second wet period of year 0 (year 1), with sharply reversed signs at either the start or the end of this rainy period, particularly in year 0 . The wind speed anomalies are consistent with the $F^{\text {net }}$ anomalies during these two second wet periods when the SST anomalies are opposed to the $F^{\text {net }}$ anomalies. These local maximum (minimum) anomalies are associated with the low-level circulation anomalies that coincide well with the eastward extension of the Asian summer monsoon trough in the second wet periods. This is evidence that the mean state affects the anomalous field. Large positive wind speed anomalies are also found near the equator around April (1) when the SST anomalies reach a minimum. Overall, the $F^{\text {net }}$ anomalies are controlled by the SST anomalies from fall (0) to May (1), but are dominated by the wind speed anomalies in the second wet periods of year 0 and year 1 .

As discussed in the previous section, the onset of the second wet period (1) tends to be delayed for several pentads; so we examine further the possible mechanisms for this delay of the onset. Figure 13a shows the variation of $F^{\text {net }}$ over the region to be dominated by the Asian summer monsoon gyre. The sharp increase in $F^{\text {net }}$ in the second wet period is a few pentads later in the $\mathrm{El}$ Niño decaying years than in normal years, consistent with the delay of the onset of the second wet period (1). We then examine the variation of the $925-\mathrm{hPa}$ wind speed, which is the main factor for controlling $F^{\text {net }}$ in the
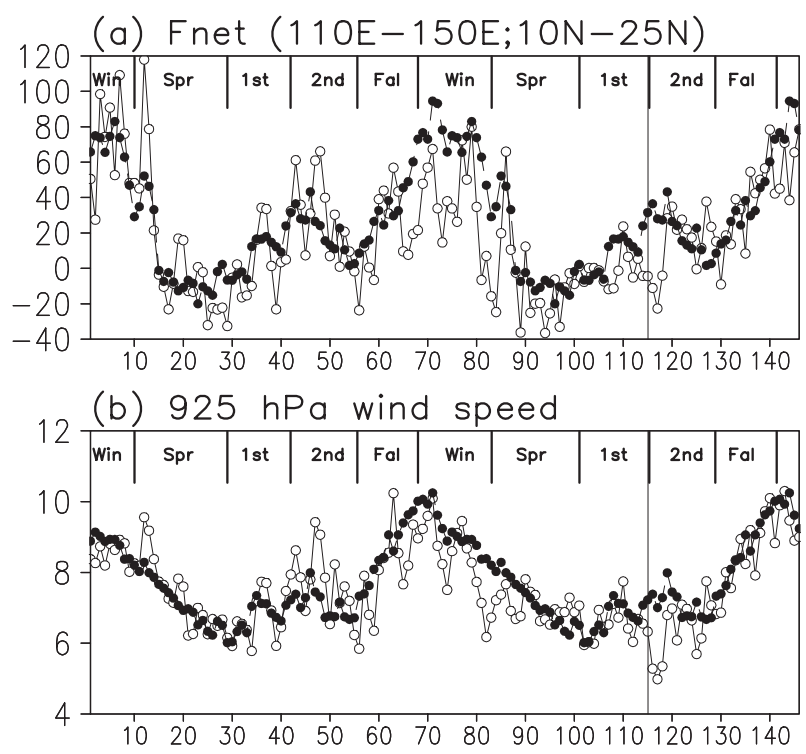

FIG. 13. The composite of the three strong El Niño events (hollow circles) and the climatology (solid circles) for the (a) net energy flux into the atmospheric column and (b) 925 -hPa wind speed averaged over $10^{\circ}-25^{\circ} \mathrm{N}$ and $110^{\circ}-150^{\circ} \mathrm{E}$. The straight lines indicate the onset of the second wet period (1).

second wet period (Fig. 13b). The wind speed is lower in the El Niño decaying years than in normal years after the normal onset time, the 42nd (115th) pentad, which is also consistent with the variation of $F^{\text {net }}$ shown in Fig. 13a. Thus, the persistence of the low-level anticyclonic circulation anomaly over the WNP reduces the wind speed and then delays the onset of the second wet period (1). In other words, the anomalous field is affecting the mean state.

Closely examining the low-level wind anomalies shown in Figs. 6 and 8, the anticyclonic circulation anomaly over the WNP in the period from fall (0) to the second wet period (1) is associated with an eastward movement of an anticyclonic circulation anomaly over the northern Indian Ocean in the second wet period (0) (Chou 2004; Chen et al. 2007). Figure 14 also implies a tendency toward an eastward movement of the anticyclonic circulation anomaly at the end of year 0 , which is particularly clear in the positive streamfunction anomalies, which have existed since the second wet period (0) around the region from $60^{\circ}$ to $90^{\circ} \mathrm{E}$ (Fig. 14). We note that the maximum easterly wind anomalies over the Indian Ocean are associated with the Indian Ocean dipole (e.g., Saji et al. 1999). This anticyclonic circulation anomaly starts to move eastward around the end of the second wet period (0) and the beginning of fall (0). This eastward movement of the low-level anticyclonic circulation anomaly is connected with the season (Chou 2004). Other studies also show that the abrupt establishment of 


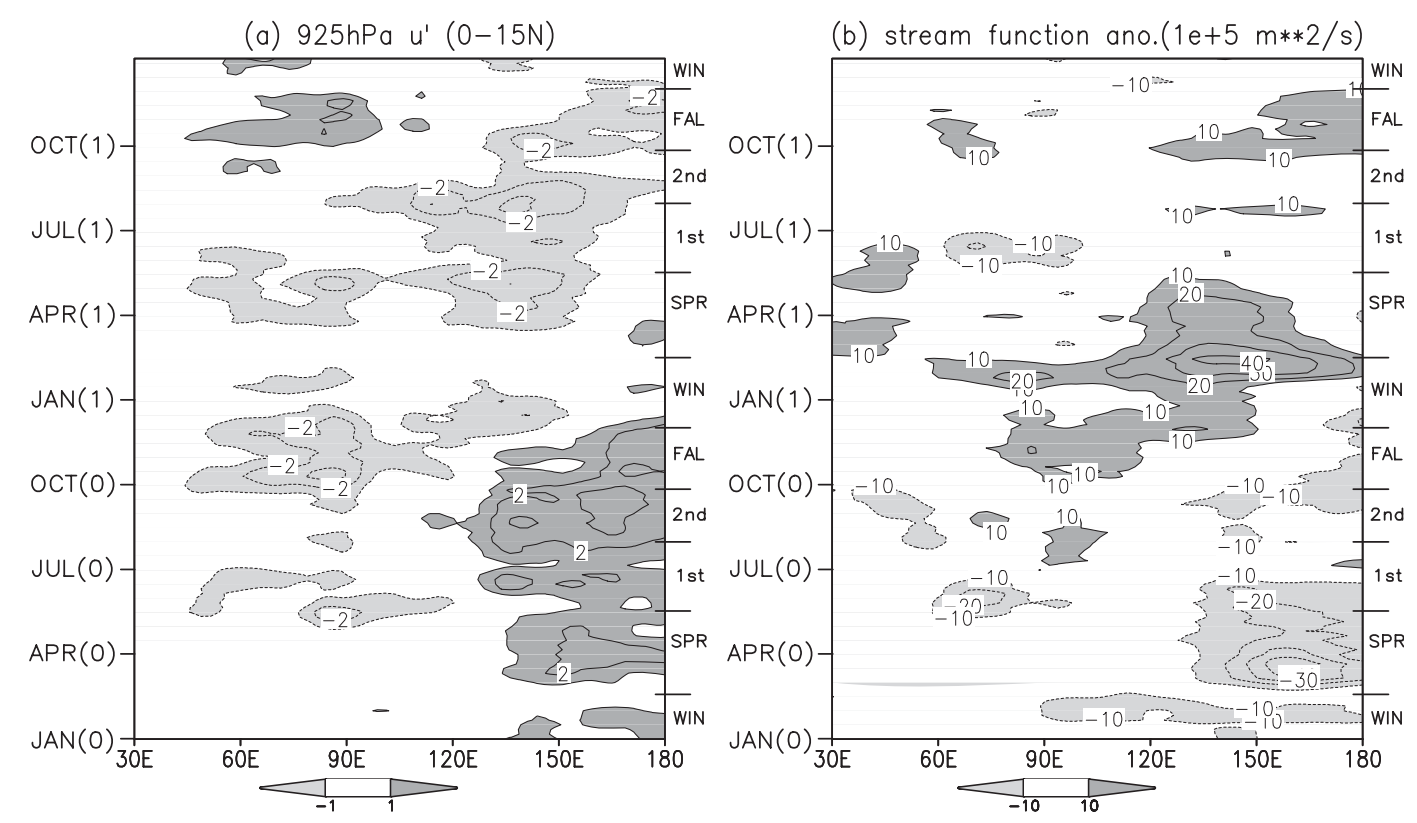

FIG. 14. Temporal variations of the composite for the anomalies of the (a) 925-hPa zonal wind and (b) 925-hPa streamfunction averaged over $0^{\circ}-15^{\circ} \mathrm{N}$.

the anticyclonic circulation anomaly over the WNP can be associated with an advective process and tropicalextratropical interaction (Lau and Nath 2006; Wang and Zhang 2002).

\section{Discussion and conclusions}

During the period of strong El Niño events with warm SST anomalies occurring over the equatorial eastern Pacific, the western North Pacific and East Asian (WNP-EA) rainfall exhibits a strong interannual variation. Over the northern part of the WNP-EA region, which is dominated by a southwest-northeast tilting rainband, negative precipitation anomalies are found from around the fall of the El Niño growing year (0) to the first wet period of the El Niño decaying year (1). Over the southern part of the WNP-EA region, which is dominated by tropical convection, the corresponding precipitation anomalies show more complicated variability. Positive precipitation anomalies are found over the Philippine Sea and the western North Pacific in both the first and second wet periods (0). On the other hand, negative precipitation anomalies occur from fall (0) to the second wet period of the following year (1). The precipitation anomalies also exhibit an intraseasonal variation in the first and second wet periods of year 0 and year 1. Even though the precipitation anomalies have a strong interannual variation, the onsets of most rainy periods vary little except for in the second wet period (1), which clearly shows a delay of onset.
The precipitation over the WNP-EA region can be affected by El Niño, mainly via low-level circulation anomalies commonly found during the El Niño period, and other processes, such as anomalous descent or subsidence associated with the upper-tropospheric circulation. The well-known low-level circulation anomalies can be induced and maintained by a weakening of the Walker circulation and local SST anomalies during the El Niño peak phase, but are associated with more complicated processes in other periods. A cyclonic circulation anomaly usually dominates the western North Pacific before fall (0), but an anticyclonic circulation anomaly quickly moves in and dominates the WNP in fall (0) when cold air associated with the northerly winds of the Asian winter monsoon circulation penetrates into this region. The anticyclonic circulation anomaly persists for around one year until the second wet period (1). The anticyclonic circulation anomaly brings relatively moist air from the south and enhances precipitation, associated with the frontal system, from fall (0) to the first wet period (1). The low-level circulation anomalies also affect tropical convection via modification of the surface heat flux exchange, such as evaporation. The anomalous tropical convection can also have a positive feedback in sustaining the low-level circulation anomalies.

Evaporation depends on the surface wind speed and moisture difference between the surface and atmosphere, which is usually dependent on SST. Over the WNP-EA region, SST anomalies are frequently a major contributing factor to the variation of evaporation, except during 
both second wet periods of year 0 and year 1 . Cold SST anomalies are found from fall (0) to the first wet period (1) when SST anomalies dominate, so the evaporation anomalies and corresponding surface heat flux anomalies are negative. During both second wet periods (year 0 and year 1), the wind speed anomalies become a major factor contributing to the variation of evaporation; the SST anomalies are a response to atmospheric conditions, such as cloud cover. In the second wet period ( 0$)$ when the low-level circulation anomaly is cyclonic, the corresponding wind speed is enhanced, so the evaporation and the corresponding surface heat flux anomalies are positive. Thus, convection is enhanced and precipitation anomalies are positive. During this period, the SST anomalies become colder because of the reduction of downward solar radiation due to more clouds and stronger evaporation. In the second wet period (1), the low-level circulation anomaly becomes anticyclonic, so the corresponding wind speed is reduced and evaporation is decreased. Thus, convection is weakened and the corresponding precipitation anomalies are negative. In this period, the SST anomalies are positive since less cloud allows more downward solar radiation and less evaporation tends to warm the ocean.

The SST-dominated evaporation anomalies are associated with a thermodynamic process in which the ocean is a forcces an atmospheric response. SST anomalies in this period are most likely affected by ocean dynamics and should not be significantly influenced by surface heat flux exchange. The wind-speed-dominated evaporation anomalies, on the other hand, are associated with a dynamic process that interacts with the atmospheric circulation. In this case, the ocean becomes a response to atmospheric forcing-not a forcing to the atmosphere. The anomalous low-level circulation can induce evaporation anomalies that enhance or reduce convection. The changed convection then affects the atmospheric circulation via latent heat release; then the atmospheric circulation is further modified. Such dynamic feedback strongly depends on the mean circulation over the WNP-EA region. For instance, an anticyclonic circulation anomaly is found after the El Niño peak phase and persists into the following summer season. During the first wet period (1), the Asian summer monsoon trough has not yet extended eastward into the WNP, so the wind speed does not change significantly and even tends to be enhanced due to the westward extension of the Pacific subtropical high over the WNP. During the second wet period (1), on the other hand, the Asian summer monsoon trough extends eastward, so the anticyclonic circulation anomaly tends to reduce the wind speed over this region. This reduced wind speed then becomes a main mechanism for the persistence of the anticyclonic circulation anomaly into the deep summer of the El Niño decaying year.

Overall, the mechanisms for inducing precipitation anomalies and the corresponding mean precipitation over both northern and southern parts of the WNP-EA region are similar in each rainy period. However, the detail processes associated with the mechanisms of the precipitation anomalies over the southern part of the WNP-EA region are more complicated and quite different from the processes of the mean precipitation. Over the southern part of the WNP-EA region, as discussed by several studies (e.g., Wang et al. 2005; Wu et al. 2006), a negative correlation between precipitation and local SST is usually found in summer over the WNP, but this negative correlation cannot be simulated by most atmospheric general circulation models (AGCMs). Thus, atmosphere-ocean coupled models are suggested to capture such a relationship over this region. Our study suggests that a well-simulated mean circulation over the WNP-EA should also be very important, particularly in the second wet period. With correct mean circulation, the anomalous circulation induced by El Niño can create the correct contribution of wind speed to surface heat flux. This is an important implication to help modelers improve simulations of the summer monsoon over the WNP-EA region.

Acknowledgments. This work was supported under National Science Council Grant 96-2628-M-001-019. The CEP-DOE Reanalysis-2 data are provided by the NOAA-CIRES Climate Diagnostics Center, Boulder, Colorado, via their Web site (http://www.cdc.noaa.gov/).

\section{REFERENCES}

Ashok, K., S. K. Behera, S. A. Rao, H. Weng, and T. Yamagata, 2007: El Niño Modoki and its possible teleconnection. $J$. Geophys. Res., 112, C11007, doi:10.1029/2006JC003798.

Chang, C.-P., Y. Zhang, and T. Li, 2000a: Interannual and interdecadal variations of the East Asian summer monsoon and tropical Pacific SSTs. Part I: Roles of the subtropical ridge. $J$. Climate, 13, 4310-4325.

$\ldots, \ldots$, and $\longrightarrow$ 2000b: Interannual and interdecadal variations of the East Asian summer monsoon and tropical Pacific SSTs. Part II: Meridional structure of the monsoon. J. Climate, 13, 4326-4340.

Chen, C.-S., and Y.-L. Chen, 2003: The rainfall characteristics of Taiwan. Mon. Wea. Rev., 131, 1323-1341.

Chen, J.-M., T. Li, and C.-F. Shih, 2007: Fall precipitation barrier of sea surface temperature in the South China Sea associated with ENSO. J. Climate, 20, 158-172.

Chen, L., M. Dong, and Y. Shao, 1992: The characteristics of interannual variations on the East Asian monsoon. J. Meteor. Soc. Japan, 70, 397-421.

Chou, C., 2004: Establishment of the low-level wind anomalies over the western North Pacific during ENSO development. $J$. Climate, 17, 2195-2212. 
— J.-Y. Tu, and J.-Y. Yu, 2003: Interannual variability of the western North Pacific summer monsoon: Differences between ENSO and non-ENSO years. J. Climate, 16, 2275-2287.

— , L.-F. Huang, L. Tseng, J.-Y. Tu, and P.-H. Tan, 2009: Annual cycle of rainfall in the western North Pacific and East Asian sector. J. Climate, 22, 2073-2094.

Chou, S.-H., M.-D. Chou, P.-K. Chan, P.-H. Lin, and K.-H. Wang, 2004: Tropical warm pool surface heat budgets and temperature: Contrasts between 1997/98 El Niño and 1998/99 La Niña. J. Climate, 17, 1845-1858.

Ding, Y., and J. C. L. Chan, 2005: The East Asian summer monsoon: An overview. Meteor. Atmos. Phys., 89, 117-142.

Geng, Q. Z., A. Sumi, and A. Numaguti, 2000: Role of transients in the dynamics of East Asian summer seasonal mean circulation anomalies-A study of 1993 and 1994. J. Climate, 13, 35113531.

Guan, Z., and T. Yamagata, 2003: The unusual summer of 1994 in East Asia: IOD teleconnections. Geophys. Res. Lett., 30, 1544, doi:10.1029/2002GL016831.

Hsu, H.-H., and X. Liu, 2003: Relationship between the Tibetan Plateau heating and East Asian summer monsoon rainfall. Geophys. Res. Lett., 30, 2066, doi:10.1029/2003GL017909.

—_, and S.-M. Lin, 2007: Asymmetry of the tripole rainfall pattern during East Asian summer. J. Climate, 20, 4443-4458.

Huang, R., and F. Sun, 1992: Impacts of the tropical western Pacific on the East Asian summer monsoon. J. Meteor. Soc. Japan, 70, 243-256.

Kanamitsu, M., W. Ebisuzaki, J. Woollen, S.-K. Yang, J. J. Hnilo, M. Fiorino, and G. L. Potter, 2002: NCEP-DOE AMIP-II Reanalysis (R-2). Bull. Amer. Meteor. Soc., 83, 1631-1643.

Kang, I., 2004: Current status of AGCM monsoon simulations. East Asian Monsoon, C.-P. Chang, Ed., World Scientific Series on Meteorology of East Asia, Vol. 2, World Scientific, 301-331.

Kawamura, R., T. Matsuura, and S. Iisuka, 2001: Interannual atmosphere-ocean variations in the tropical western North Pacific relevant to the Asian summer monsoon-ENSO coupling. J. Meteor. Soc. Japan, 79, 883-898.

Lau, K.-M., 1992: East Asian summer monsoon rainfall variability and climate teleconnection. J. Meteor. Soc. Japan, 70, 211-241.

, and W. Bua, 1998: Mechanism of monsoon-Southern Oscillation coupling: Insights from GCM experiments. Climate Dyn., 14, 759-779.

— summer rainfall over China: An assessment of the regional impacts of the 1997-98 El Niño. J. Climate, 14, 1294-1308.

— bility of the Asian summer monsoon: A reassessment of the monsoon-ENSO relationship. J. Climate, 14, 2880-2895.

—, K.-M. Kim, and S. Yang, 2000: Dynamical and boundary forcing characteristics of regional components of the Asian summer monsoon. J. Climate, 13, 2461-2482.

Lau, N.-C., and M. J. Nath, 2000: Impact of ENSO on the variability of the Asian-Australian monsoons as simulated in GCM experiments. J. Climate, 13, 4287-4309.

$\longrightarrow$, and — 2006: ENSO modulation of the interannual and intraseasonal variability of the East Asian monsoon-A model study. J. Climate, 19, 4508-4530.

,-- , and H. Wang, 2004: Simulations by a GFDL GCM of ENSO-related variability of the coupled atmosphere-ocean system in the East Asian Monsoon region. East Asian Monsoon, C.-P. Chang, Ed., World Scientific Series on Meteorology of East Asia, Vol. 2, World Scientific, 271-300.
Li, T., Y. C. Tung, and J. W. Hwu, 2005: Remote and local SST forcing in shaping Asian-Australian monsoon. J. Meteor. Soc. Japan, 83, 153-167.

LinHo, and B. Wang, 2002: The time-space structure of the AsianPacific summer monsoon: A fast annual cycle view. J. Climate, 15, 2001-2019.

Liu, X. D., and M. Yanai, 2002: Influence of Eurasian spring snow cover on Asian summer rainfall. Int. J. Climatol., 22, 1075-1089.

Meehl, G. A., J. M. Arblaster, and J. Loschnigg, 2003: Coupled ocean-atmosphere dynamical processes in the tropical Indian and Pacific and the TBO. J. Climate, 16, 2138-2158.

Nitta, T., 1987: Convective activities in the tropical western Pacific and their impacts on the Northern Hemisphere summer circulation. J. Meteor. Soc. Japan, 65, 165-171.

_ its association with $500-\mathrm{hPa}$ height and tropical convection. $J$. Meteor. Soc. Japan, 74, 425-445.

Park, C.-K., and S. D. Schubert, 1997: On the nature of the 1994 East Asian summer drought. J. Climate, 10, 1056-1070.

Reynolds, R. W., N. A. Rayner, T. M. Smith, D. C. Stokes, and W. Wang, 2002: An improved in situ and satellite SST analysis for climate. J. Climate, 15, 1609-1625.

Ropelewski, C. F., and M. S. Halpert, 1987: Global and regional scale precipitation associated with El Niño/Southern Oscillation. Mon. Wea. Rev., 115, 1606-1626.

Saji, N. H., and T. Yamagata, 2003: Possible impacts of Indian Ocean dipole events on global climate. Climate Res., 25, 151-169.

_ B. B. Goswami, P. N. Vinayachandran, and T. Yamagata, 1999: A dipole mode in the tropical Indian Ocean. Nature, 401, 360-363.

Shen, S., and K.-M. Lau, 1995: Biennial oscillation associated with the East Asian summer monsoon and tropical sea surface temperatures. J. Meteor. Soc. Japan, 73, 105-124.

Su, H., J. D. Neelin, and C. Chou, 2001: Tropical teleconnection and local response to SST anomalies during the 1997-1998 El Niño. J. Geophys. Res., 106, 20 025-20 043.

Sumi, A., M. Kimoto, and X. Shen, 2004: Simulation studies of the Asian monsoon using the CCSR/NIES AGCM. East Asian Monsoon, C.-P. Chang, Ed., World Scientific Series on Meteorology of East Asia, Vol. 2, World Scientific, 331-353.

Tanaka, M., 1997: Interannual and interdecadal variations of the western North Pacific monsoon and the East Asian baiu rainfall and their relationship to ENSO cycles. J. Meteor. Soc. Japan, 75, 1109-1123.

Tian, S.-F., and T. Yasunari, 1992: Time and space structure of interannual variations in summer rainfall over China. J. Meteor. Soc. Japan, 70, 585-596.

Wang, B., and J. C. L. Chan, 2002: How ENSO regulates tropical storm activity over the western North Pacific. J. Climate, 15, 1643-1658.

— , and Q. Zhang, 2002: Pacific-East Asian teleconnection. Part II: How the Philippine Sea anomalous anticyclone is established during El Niño development. J. Climate, 15, 3252-3265.

- R. Wu, and X. Fu, 2000: Pacific-East Asian teleconnection: How does ENSO affect East Asian climate? J. Climate, 13, $1517-1536$

$\longrightarrow$, - and K.-M. Lau, 2001: Interannual variability of the Asian summer monsoon: Contrasts between the Indian and the western North Pacific-East Asian monsoons. J. Climate, 14, 4073-4090.

_ Q Q. Ding, X. Fu, I.-S. Kang, K. Jin, J. Shukla, and F. DoblasReyes, 2005: Fundamental challenge in simulation and prediction 
of summer monsoon rainfall. Geophys. Res. Lett., 32, L15711, doi:10.1029/2005GL022734.

Watanabe, M., and F.-F. Jin, 2002: Role of Indian Ocean warming in the development of Philippine Sea anticyclone during ENSO. Geophys. Res. Lett., 29, 1478, doi:10.1029/2001GL014318.

Weng, H., K.-M. Lau, and K.-K. Xue, 1999: Multi-scale summer rainfall variability over China and its long-term link to global sea surface temperature variability. J. Meteor. Soc. Japan, 77, 845-857.

- K. Ashok, S. K. Behera, S. A. Rao, and T. Yamagata, 2007 : Impacts of recent El Niño on Modoki dry/wet conditions in the Pacific rim during boreal summer. Climate Dyn., 29, 113-129.

$\mathrm{Wu}, \mathrm{R}$., and B. Wang, 2000: Interannual variability of summer monsoon onset over the western North Pacific and the underlying processes. J. Climate, 13, 2483-2501.

- and B. P. Kirtman, 2007: Observed relationship of spring and summer East Asian rainfall with winter and spring Eurasian snow. J. Climate, 20, 1285-1304.
- Z.-Z. Hu, and B. P. Kirtman, 2003: Evolution of ENSO-related rainfall anomalies in East Asia. J. Climate, 16, 3742-3758.

— B. P. Kirtman, and K. Pegion, 2006: Local air-sea relationship in observations and model simulations. J. Climate, 19, 4914-4932.

Xie, P., and P. A. Arkin, 1997: Global precipitation: A 17-year monthly analysis based on gauge observations, satellite estimates, and numerical outputs. Bull. Amer. Meteor. Soc., 78, 2539-2558.

Yeh, M.-C., and T.-C. Chen, 2000: Seasonal variation of the rainfall over Taiwan. Int. J. Climatol., 20, 803-809.

Yoo, S. H., S. Yang, and C. H. Ho, 2006: Variability of the Indian Ocean sea surface temperature and its impacts on AsianAustralian monsoon climate. J. Geophys. Res., 111, D03108, doi:10.1029/2005JD006001.

Zhang, R., and A. Sumi, 2002: Moisture circulation over East Asia during El Niño episode in northern winter, spring and autumn. J. Meteor. Soc. Japan, 80, 213-227. 